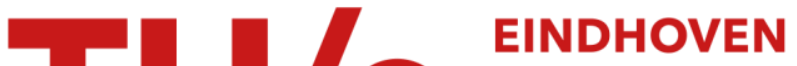 UNIVERSITY OF TECHNOLOGY
}

\section{Quality assurance of joint replacement : legal regulation and medical judgement}

Citation for published version (APA):

Faro, L. M. C., \& Huiskes, H. W. J. (1992). Quality assurance of joint replacement : legal regulation and medical judgement. Acta Orthopaedica Scandinavica. Supplementum, 63(S250), 1-33.

https://doi.org/10.3109/17453679209155045

DOI:

10.3109/17453679209155045

Document status and date:

Published: 01/01/1992

Document Version:

Publisher's PDF, also known as Version of Record (includes final page, issue and volume numbers)

Please check the document version of this publication:

- A submitted manuscript is the version of the article upon submission and before peer-review. There can be important differences between the submitted version and the official published version of record. People interested in the research are advised to contact the author for the final version of the publication, or visit the $\mathrm{DOI}$ to the publisher's website.

- The final author version and the galley proof are versions of the publication after peer review.

- The final published version features the final layout of the paper including the volume, issue and page numbers.

Link to publication

\section{General rights}

Copyright and moral rights for the publications made accessible in the public portal are retained by the authors and/or other copyright owners and it is a condition of accessing publications that users recognise and abide by the legal requirements associated with these rights.

- Users may download and print one copy of any publication from the public portal for the purpose of private study or research.

- You may not further distribute the material or use it for any profit-making activity or commercial gain

- You may freely distribute the URL identifying the publication in the public portal.

If the publication is distributed under the terms of Article $25 \mathrm{fa}$ of the Dutch Copyright Act, indicated by the "Taverne" license above, please follow below link for the End User Agreement:

www.tue.nl/taverne

Take down policy

If you believe that this document breaches copyright please contact us at:

openaccess@tue.nl

providing details and we will investigate your claim. 


\section{Introduction}

“...under current standards of nonregulation in the United States, I could take a paperclip and fashion it into an IUD (Intra Uterine Device). I could begin inserting it into women without even informing them that it is an experimental and never-tested IUD, and I would not even have to inform the FDA of my newly invented IUD."

(Thompson 1976)

A couple of years ago, the following statement was made in an editorial of the Acta Orthopaedica Scandinavica: "The pioneer years are over, and the public has a right to be assured that artificial implants do not introduce unexpected hazards associated with poor design, incompatible materials, or deficient manufacturing procedure and quality control." In the same editorial, concern was expressed that at that moment there was insufficient assurance that implants supplied by a highly competitive market were properly manufactured (Editorial 1987). This, as well as Dr. Thompson's statement, clearly indicate the vagaries of an "unregulated" situation with regard to the safety of medical devices.

In some countries, law systems were drafted with the objective of giving the public assurance about safety and effectiveness of medical devices. In the United States of America, quality assurance is principally government controlled and based on the Medical Device Amendments of 1976. In France, regulatory requirements apply only to a limited number of medical devices. Some European countries, like the Netherlands or Sweden, still have the status of "paper clip country:" there is no legal quality assurance system for medical devices at all.

"Overregulation" will have negative effects, for instance for innovation; new developments, beneficial to the patient, may be retarded by rigid regulatory requirements. Thomas Gluck, in 1890, could introduce his knee prosthesis and was not bothered by an American FDA, a German TUV or any other government body. But for example bone cement with antibiotics was already in widespread use in Europe while in the United States the FDA was reluctant to allow it on the market.

Conversely, a system with no regulatory control at all allows all devices on the market, regardless of whether there is evidence regarding safety and effectiveness. Of course, even strict regulation is not an absolute guarantee against disasters. We all remember the Björk-Shiley heart valves and more recently the safety issues of breast implants. These have shown that the law can not guarantee absolutely safe medical devices. After obtaining market approval for a device, there is a continuous need for research and registration of complications. The responsibility with regard to this task lies not only with the government but also with the medical community.

Evidently, much has changed since the time that Dr. Thompson made the above remarks. In the United States, the Medical Device Amendments have been enacted, although the costs-to-benefit ratio of this system is not always appreciated. But compared to an unregulated situation as illustrated by Dr. Thompson, the benefits should be beyond any doubt.

In our research we investigated the legal situation in several countries. We carefully examined the contents and results of the regulatory requirements which specifically apply to orthopedic implants. The law systems of the United States, France, the Netherlands, the United Kingdom, Germany, and the future system of the European Community were analyzed. The United States and the Netherlands were chosen as examples of vastly diverging systems with detailed requirements (United States), on the one hand, and with no requirements at all (the Netherlands) on the other. The French system was analyzed because of the fact that it appears to be a mixture of government control and self regulation. In contrast, regulation in the United Kingdom is based on a voluntary system of compliance with procurement specifications and specified standards (hence, there is no government regulation of medical devices). After 1992 (or probably later), the system of the European Community will govern the legal quality assurance systems of all member states; this will be the end of the "paperclip" status of European Community members states. The consequences of these developments in the field of joint prostheses were studied.

In order to be able to determine what has to be regulated with regard to an effective quality assurance system, the concept of "quality" had to be disentangled and defined first. In order to do so, we used the life cycle model as an analytical tool. During each stage of the life cycle we analyzed the factors which have an influence on quality. With regard to the fact that government control may not always be the most effective instrument in quality assurance, we studied alternatives for government regulation and examined the possibilities for self regulation. 


\section{Innovation, quality, and regulation}

\section{The pioneer years}

\section{Introduction}

The pioneers in joint replacement, such as Chamley, Müller, Ring and others, engaged in prosthetic design processes of trial-and-error. Some were highly successful. Some were not. It was impossible to predict the consequences of the material and design choices they made. It was also impossible to estimate the long-term viability of their inventions from the initial clinical results. In a way, these innovators engaged in adventurism, like all pioneers do. In those days, there was a clear justification for adventurism, since very little comfort could be offered to the severely disabled victims of joint diseases. In our day and age, however, the picture has changed. Owing to the clinical experience of the last 20 years we have learned much about fixation-failure mechanisms, about bone reactions, and about adverse effects of biomaterials. A discussion of implant regulation would not be complete without the consideration of this clinical and scientific history, and a consideration of how this knowledge can be consolidated and applied consistently to decide under what circumstances joint replacements can be brought on the market.

\section{Trial and error}

The history of total joint replacement using foreign materials probably started around 1890 , when Thomas Gluck used ivory to replace joints. Later, several concepts and materials were experimented with by wellknown surgeons, like, for instance, Smith- Peterson, Wiles, Judet, Moore, McKee and Charnley. They conceived of new developments out of a need to help their patients, for whom there was no successful cure available. They designed their prostheses, they choose the materials, tested the prototypes and tried them clinically. They were "inventive users" (Von Hippel 1976). When they were unsuccessful or not fully satisfied, they attempted to improve the product or procedure, based on the knowledge they gathered from their clinical trials: a developmental process of "trial and error." Failures were inevitable and unfortunate, of course, but the patients were usually made aware of the risks and had no alternatives, while every failure provided a lesson for further advancement.

The "inventive users" were also the ones who decided when and how to make their methods and devices available to other surgeons. This question of when "marketing" could start would depend, on the one hand, on the satisfaction of the inventor with his product and his ideas about the probability of success for other users, and on the other hand on the needs of the patients and the urge of the inventor and his colleagues to help them. This decision would then involve the capacity of self-critique and judgement, vanity and the appreciation of risks. Hence, the decision would have been made differently by different individuals. Some would feel confident enough to commercialize their devices and spread them widely over the orthopedic community. Others would feel more reluctant, and adapted a very restricted policy, whereby surgeons were required to be trained and their results checked by the innovator himself, a policy followed by Charnley, widely seen as the most successful eariy innovator. This question of how and when to commercialize is extremely important, both for the safety of patients and the viability of new concepts, as illustrated by the following example.

\section{The Judet prosthesis as an example of a "disaster" in implant surgery}

The Judet acrylic femoral head prosthesis was introduced in 1946 by Jean and Robert Judet. At first their invention seemed to be a promising one. The operation was simple to perform and the immediate results were good. The technique was soon taken over by orthopedic surgeons all over Eurrope. Nissen, in his foreword to the English edition of the Judets' book on this prosthesis, wrote: "In no time surgeons already familiar with the problem of reconstruction of the hip found they could obtain good early results for a comparitively modest expenditure of time and effort; so it came to pass that despite all cautionary advice, enthousiasm often outstripped judgement" (Judet et al 1954). At the time that the English version was published, the Judets had operated on about 850 patients. Already there were signs that the operation was not such a great success as expected. A short time after the operation, the acrylic started to wear and break in many patients (Scales 1967). The method of fixation was inadequate and subsequent operations to revise the prosthesis were difficult, and the results were unsatisfactory. There and above, in some countries sometimes bizarre modifications of the prosthesis appeared: "very different from the simple one to which Macfarland once referred as 
"le petit champignon Judet" and frequently the whole procedure bore only a general resemblance to the one described in this book" (Nissen 1954).

In retrospect, the Judet procedure is sometimes considered "one of the greatest disasters in surgery" (Scales 1967). In 1954, a debate was held by the British Orthopaedic Association on the following motion: "In the opinion of this house all methods of arthroplasty of the hip have failed to achieve their purpose." The motion was proposed by Mr. K. I. Nissen who based his attack on hip arthroplasty mainly on the early detoriation of the results and on the serious postoperative complications that might occur. In spite of "spirited support" and "the considerable number who finally voted in agreement with it, few could be found to speak wholeheartedly in its favour" (British Orthopaedic Association 1954). The motion was subsequently lost by a substantial majority. In the debate Merle d'Aubigne held the opinion that all the failures of arthroplasty were due to technical errors. It would take perhaps 200 arthroplasties to learn the art. Judet stated that fractures of the prosthesis were now seldom seen in France and he attributed this to a better acrylic resin. Remarkable at this time, Charnley was still in favour of the motion as he was still very sceptical about the possibility of a successful arthroplasty ever being developed (Waugh 1990).

\section{Discussion and conclusions}

Although the Judet prosthesis may be called a "failure" and appeared to be a disaster for many patients, it stimulated innovation and urged many forward to improve arthroplasty (Scales 1967). It was acknowledged by many surgeons that collaboration with engineers was essential if any kind of artificial joint was to succeed (Waugh 1990). According to Le Vay, good results were to be expected eventually, if the necessary preliminary research was made in animals and man into the relevant mechanical, chemical and biological factors with accelerated wear tests (Le Vay 1990).

Because he was very cautious about the prospects, it was several years after the failure of the Judet prosthesis had become apparent, that Charnley introduced his "low friction" arthroplasty, In the beginning he experimented with polytetrafluorethylene (PTFE). It appeared that this material wore and tissue reactions similar to other plastic materials were found. When he found out about the problems with PTFE he immediately abandoned the use of it and alerted the orthopedic community (Charnley 1963). In this way, widespread use and subsequent disasters were probably prevented.

The fates of the Charnley and the Judet prostheses were very much determined by the way in which, and the time at which, they were marketed. The decisions taken to this effect were individual ones, for which only the surgeons involved were responsible. They were both pioneers and adventurers, and both experiments have contributed enormously to the development of total joint replacement. Although Charnley was more careful and successful, he could learn from the negative experiences of the Judet brothers, both where it concerned the design and materials of the prosthesis, and the time and method of marketing. Hence, the Judet prosthesis may have been a failure necessary for the later success of others.

\section{Innovation today}

\section{The game and its rules}

Today the question of how and when to market a jointreplacement device is as important as ever. Innovation, however, must be seen in a very different light and there is no longer room for adventurism. This is caused by two important changes. First of all, where there was no cure for the severe joint diseases earlier, there is one now, the "conventional" cemented total joint replacement. Hence, where earlier it could be ethically acceptable to put the safety of patients at risk in order to cure them from severe pain and disability, now every risk must be measured against the option of an, at least reasonably predictable cure.

Secondly, the development and marketing of totaljoint prostheses has become an enormously profitable business, in which many companies are involved. Where earlier the pioneers, the "inventive users", "called the tune" where it concerned design, materials choice, production, testing and marketing of a prosthesis, now an inventive authorship can hardly succeed without a commercial partnership. Such partnerships are not just subject to medical, but also to commercial rules. In other words, companies need profits in order to survive, requiring sales. A "good" prosthesis for a company is one that sells well.

There is nothing wrong with these partnerships in principle. Without them, innovation and development would falter. The problem is not in the game itself, but in its rules. We have no quarrel with surgeons engaged in prosthetic development, nor with their commercial partners. Our central thesis of this monograph, however, is that the question of how and when to market their innovations should not be entirely their decision only.

\section{Failures and disasters}

There is a fair number of failures, less successful prostheses, or even "disasters" in the more recent literature. 
A notorious example is hip surface replacement, for which a number of prosthetic devices were marketed (Wagner 1978, Freeman 1983, Amstutz et al 1984). Surface replacement was considered a more conservative approach, with the particular advantages that much less bone was to be removed-hence a better "second line of defense" if revisions were necessary-and that stress patterns in bone would be closer to normal, hence less adverse bone remodeling would occur (Wagner, 1978) These advantages, particularly for the younger patients, were "intuitively obvious" and after only a relatively brief period of clinical trials it was introduced in the market, and absorbed massively. In Europe, busses were hired to take orthopaedic surgeons to Heidelberg, to learn the technique from Dr. Wagner and apply it at home. This led to disastrous results in many patients, due to aseptic loosening of acetabular or femoral components, or both, often associated with femoral-neck fractures. In the statistics, early failures became evident after 5 to 7 years in retrospective studies (Head 1981, Mogensen et al 1982, Schreiber and Jacob 1984, Freeman 1983, Strens 1986). Causes were not clear. Hypotheses have been suggested, however, based on excessive wear particles, stress-transfer and stress shielding, acetabular-cup flexibility, interrupted vascularity and technical difficulties during the operation (Head 1981, Freeman 1983, Schreiber and Jacob 1984, Huiskes et al 1990). The expectation that revisions would be easy was belied as well: many patients received Girdle stones afterwards (Strens 1986). The surface replacements are now virtually extinct.

Another drama, which ran for some time in the Scandinavian countries in particular, was the Christiansen total-hip replacement. This trunnion-bearing hip prosthesis was popular in Sweden, where 5,095 were implanted from 1973-1983, of which 1,365 were revised by 1986 (Ahnfelt et al 1990). The Wagner resurfacing prosthesis and the Christiansen prosthesis were subject to the most revisions, with 10 years survival rates of 28 and 63 percent respectively, as found in the Swedish multi- center study of Ahnfelt et al (1990). The authors estimated that, apart from patient-suffering, the Christiansen disaster has cost the Swedish community USD 20 millions, which could have been saved if another prosthesis had been used instead.

The Mittelmeier hip joint was marketed in Europe and later also in the USA. It was a noncemented prosthesis with ceramic head and cup. The stem differed from the usual designs, consisting of a "lattice" structure with large holes to allow for bone to grow in (Mittelmeier 1984). Many surgeons, particularly in Europe, were charmed by its philosophy and used it for their patients. Unfortunately, however, early loosening was common, probably due to the adverse stem design
(Feith and Megens 1986, Leary 1988), and it has eventually been taken off the market.

Cemented prostheses met adverse developments as well. In the USA the concept of femoral stem flexibility was introduced to ensure proximal load transfer, for which slender stem designs made out of titanium were marketed. Unfortunately, early loosening occurred more frequently (e.g. Robinson et al 1989, Ebramzadehh et al 1992). Similarly, metal backing was introduced for cemented acetabular cups, as a cure against frequent cup loosenings (Harris and White 1983). Eventually, however, loosenings were more frequent with metal backing than without it (Ritter et al 1990); not exactly a "disaster," but certainly one of many "cures" introduced in the last ten years which turned out to be worse than the "disease."

What could potentially turn into a disaster are the porous coatings for bone ingrowth in noncemented total-hip and knee replacements, which are now used in large numbers. Again, little can be said against their philosophy, but it is becoming clear that bone ingrowth does not occur reproducibly. Retrieval studies have shown that ingrowth around the femoral stem seldom covers more than $20 \%$ of the surface (Cook et al 1988). Maybe that will show to be enough for long-term fixation, but the point is that we do not know that for certain. In view of the number of these prostheses used now all over the world, particularly for the younger patients, this is a rather scary thought. In tibial knee components, ingrowth into porous coatings is frequently nonexistent, and many have shown instable postoperative behavior (Ryd 1986).

The above examples concerned mostly innovations initiated by surgeons - "inventive users"-in collaboration with companies. In other cases, the companies alone produced new developments, usually in new materials. Particularly in this area, real progress has been made; however, failures have also been produced. An example was the introduction of carbon-reinforced polyethylenes, stronger than the original UHMWPE, and used in acetabular cups and tibial plateans. Unfortunately, however, apart from being stronger, this material is also stiffer. As a result, it deforms less, hence contact regions do not enlarge as much under loading. Less contact region implies higher stresses, resulting in failures and increased wear. And indeed, increased wear occurred with these materials and they are no longer used.

A similar fate befell the polyethylene of the (metalbacked) PCA tibial component, which was given a surface heat treatment at the factory, in order to create a smoother surface which presumably would wear less easily. Many of these prostheses have shown excessive early wear and failure, however (Engh 1988, Wright et 
al 1992, Tulp 1992). Tulp (1992) concluded from an investigation of this prosthesis and patients who received it, that the failures were caused by a combination of three factors. First of all the surface heat treatment created a less flexible contact region and material discontinuities below the surface. Secondly, the UHMWPE inserts were often too thin and thirdly, the contact region was relatively small. These factors together produce high contact stresses, resulting in delamination of the top surface layer. Tulp (1993) also found that in a large number of cases, the surgeons concerned did not follow the alignment and implantation procedure as instructed by the manufacturer in the right way, leading to malalignment of the prosthesis, unilateral loading, and possibly early failures. This finding emphasizes the notion that a (potentially) safe device does not necessarily imply a safe joint replacement, since surgical factors are at least as important for longterm success.

This was just a quick inventory of failed innovations that come to mind easily and are relatively well known. There are numerous other examples of prostheses marketed, later to be withdrawn without any public reports of clinical results. The initiative to market products has shifted from individual surgeons, "inventive users," to orthopedic companies in modern times; however, "author-surgeons" are still involved. Whether the patients have benefitted from these developments can seriously be doubted. In fact, two recent Editorials (Bauer 1992, Goodfellow 1992) argued that all recent "improvements" notwithstanding, earlier designs were still safer for routine use, notably the Charnley hip, and the Marmor and the Total Condylar knees.

\section{Preclinical testing and clinical trials}

Considering the above examples, the question arises whether the failures and "disasters" could have been prevented; that is to say, from a scientific, technological or clinical point of view. The question falls apart in three stages, namely whether we can prevent a faulty product to be implanted in humans at all, whether we can detect errors before a product becomes freely available on the market, and whether we can, once it is on the market, detect early if a product produces a problem which may turn into a disaster.

The first stage could potentially be addressed by methods of "preclinical testing", either using animal experimentation, laboratory tests or numerical (computer) analysis. The application of these methods has great potential, but has been hampered by two problems. First of all, it should be appreciated that, contrarily to drugs, implants are not metabolized by the body. Hence, there is no time limit for adverse reactions to occur. In fact, many problems only emerge on the long term. Adverse reactions to wear particles, for example, such as implant/bone interface lysis, can only be found after many particles have been collected in a relatively long functional period of time. This problem of permanent presence of the "cure" hampers the successful application of animal experimentation as a sieve for clinical use of implants.

Secondly, no preclinical test method is useful without a very precise definition of test objectives and criteria. Although often heard in clinical circles, the loose approach of "...let's see how this prosthesis holds out in the dog (or: in the laboratory, or: in the computer)..." is virtually useless. In order to define test objectives and criteria, failure mechanisms must be known. For example, if the relationship between the characteristics of wear particles, their production rate and bone lysis were known, a preclinical laboratory test using joint simulators could be set up to measure wear rates and particle characteristics, and a particular safety criterion could be defined and applied to decide whether a particular prosthesis could be tried in humans. Similar considerations limit the applicability of preclinical tests for other failure modes.

Considering the failures described above, it is not always easy to decide with hindsight if preclinical tests could possibly have prevented them. Since the precise-or predominant-failure mechanism of surface replacements is still subject to debate, it is not probable that they could have been prevented without clinical trials. However, in animal (goat) experiments carried out later, they did fail (Strens 1986). It is also a fact that surface replacements were supposed to create relatively normal stress distributions in the bone. This theoretical proposition could certainly have been tested in a finite-element analysis, as it was established later in such studies that this proposition was wrong (Schreiber and Jacob 1984, Huiskes et al 1985, 1990). Such a preclinical 'design validation' would have been helpful, as it would have made surgeons more careful.

Preclinical testing of the philosophy of 'flexibility' for hip stems could also have been helpful. Although loosening mechanisms of cemented prostheses were not altogether well understood, finite-element or laboratory testing would have picked up excessive stresses in the proximal cement; a reason for caution (Huiskes 1990). Conversely, metal-backed acetabular components were pre-clinically tested by finite- element analyses (Pedersen et al 1982), based on which it was suggested that they would be advantageous. Now here is a clear example of a preclinical test in which the wrong criteria were used, because at the time, not enough was known about failure mechanisms. Although the information provided based on the analyses was correct, it 
was incomplete with hindsight, and the wrong decisions were made. Another example is porous coated implants, which were tried extensively in animals, before being used clinically. The precise ingrowth and loosening mechanisms of this fixation modality are not fully clear as yet, but it seems that the results are more consistent in animals than they are in humans. Where it concerns the 'improved' polyethylene materials and production technologies which failed, one would assume that extensive testing in laboratory joint simulators would have uncovered the deficiencies (Tulp 1993).

The experience-and, indeed, common senseshows that pre-clinical testing is a powerful vehicle for 'design validation' and for checking devices for wellknown failure modes. In other words, it can be used to determine if a prosthesis is likely to perform in accordance with a particular claim made by the inventor or the manufacturer, and if it is likely to suffer from particular, well-defined problems. Hence, it can be used to predict whether a device is not safe or not effective. It can not be used to determine whether a device is safe and effective.

Nevertheless, as more is becoming known about long-term failure mechanisms and their relationships with prosthetic design and material characteristics, surgical techniques and patient characteristics, preclinical testing methods are becoming more widely applicable to uncover potential problems beforehand (Huiskes 1990). Pre- design computer-simulation methods as finite-element analysis and bone-remodeling simulation methods can predict probabilities for overloading and failures of implant components, bone and interfaces, excessive bone resorption and relative interface motions. Trial implantations, either in bone specimens or simulated in computer- graphics analyses can pick up deficiencies of fit. Laboratory bench tests with prototypes can be used to measure bone and prosthetic stresses and relative motions. Joint motion simulators can be applied to test new materials for wear properties and animal experiments can check them for biocompatibility. Although again, none of these tests, if positive, can guarantee that no other problems could occur; problems the nature of which could not have been foreseen.

The second stage of failure prevention involves the question whether errors can be detected in clinical trials before a product becomes freely available on the market. The answer really depends on the quality of the trials, their duration and the number of patients involved. Again the success of clinical trials is hampered by the permanence of the cure: problems may evolve very late post-operatively, and very few inventors or manufacturers will look forward to 20 years of testing. When using the "traditional" clinical evaluation methods like the (subjective) pain and functional scoring systems, and (imprecise) radiographic techniques, however, one may wonder if a follow-up period of five years is enough to determine if an innovation works in practice.

Fortunately, new clinical investigative tools have been developed to allow for early detection of prosthetic behavior. Examples are dual-energy $\mathrm{X}$-ray absorptiometry (Kiratli 1991, Engh et al 1992), which allows for precise measurements of bone apposition and resorption around prostheses, or the application of digitization of radiograms, producing reasonably accurate longitudinal analyses of prosthetic migration and relative motions (Dooley et al 1992). An extremely potent, but more tedious method is roentgen stereophotogrammetric analysis (RSA), which involves implantation of tantalum markers and allows for very precise assessments of prosthetic migration and relative motions. In using this method, fixation deficiencies can be detected within three to six months (Ryd 1986).

When considering again the 'modern failures' discussed above, it is likely that many of the devices concerned would not have been marketed if clinical trials of adequate duration, quality and extent had been performed. However, even if the clinical trials produce positive results, there is still no guarantee that problems will not occur once the device is available on the market. First of all, as said, the problems may be of such a kind that they simply do not show up for the duration of the trial, but only on the longer term. Secondly, it is possible - and not uncommon - that the "average" surgeon produces inferior results with a device which works well in the hands of the "author-surgeon" or others who performed the clinical trials (Rothman et al 1990). This may simply be the result of the extra care, routine and know-how which are naturally associated with the performance of clinical trials, a form of clinical research. So the third stage of failure prevention involves the question whether an unsafe device, which is on the market, can be prevented from creating a "disaster". That the answer to this question is affirmative has been shown in Swedish patient outcome studies based on central registration of patients, joint-replacements and revision data (Ahnfelt et al 1988, 1990). A system like this requires a unique identification number for each patient, traceable throughout the country, and central administration and analysis of data forms for each surgical procedure, be it primary implantation or revision of a joint replacement. When the data forms contain information about implant types, surgeons, and patient characteristics, analyses of failure rates can be determined for each type of prosthesis, and correlated with other information. 
In other countries, where such a registration sysiem does not exist, information about unsafe (or unsuccessful) devices is spread through publications in the professional journals, reports at conferences or informal 'rumors'. Since the manufacturers or marketing companies are usually aware of the performance of their products, it is possible in principle that they would take unsafe devices off the market in an early stage, after the first information of failures emerges. However, it is known to us that in many cases they have been reluctant to do so.

\section{Summary and conclusion}

From a scientific, clinical and technological point of view, the risk that unsafe devices are tried in patients can be limited by the application of modern methods of pre-clinical testing, although these methods can not predict all adverse consequences of innovative products. Clinical trials of adequate duration, quality and extent, using advanced methods of patient evaluation can, conceptually, prevent unsafe devices to become available on the market. Central, mandatory registration and analysis can prevent unsafe devices on the market to create a disaster.

Our brief review shows that the application of these kinds of measures would certainly not be wasted. It is evident from past experiences that leaving the application of adequate measures to the discretion of individual innovators and manufacturers on a voluntary basis, will probably not work. Applying these measures consistently on a mandatory basis, however, requires some sort of regulation, based on standards, as discussed in the next sections. It is obvious, however, that standardization and regulation introduce bureaucracy which must, inevitably, have its effect on the effectiveness and efficiency of the innovative process.

\section{Quality and regulation}

"Quality," they all said. Uncanny. And when he asked them to define what they meant by Quality, he got the same answer too.

"I know it when I see it," they all said. Uncannier (Guaspari 1985).

\section{The concept of "quality"}

In this study the focus is on policies and regulations necessary to assure and improve the quality of total joint replacement. In general, quality is a rather vague and abstract concept and is almost impossible to define. Pirsig concludes that we all know what quality is and we will recognize it when we see it: ".... even though quality cannot be defined, you know what it is" (Pirsig 1974). Another statement in this sense is that "quality is like good wine: we know immediately upon tasting whether it has gone sour" (Munchow 1986). Relative to a joint prosthesis we would, according to this view, immediately recognize a good one when seeing it.

For considerable time the concept of quality has been discussed by several disciplines in science. Philosophers focus on problems of definition, economists on profit maximization, marketing people on buying behaviour and consumer satisfaction, and operations managers on engineering and manufacturing control (Garvin 1988). Garvin uses five general approaches to the quality of a product. According to the transcendent approach, quality is regarded as an absolute and universally recognizable concept. It is synonymous with "innate excellence." Tuchman defines it as: "... a condition of excellence implying fine quality as distinct from poor quality" (Tuchman 1980). In this philosophical approach quality is used as a basic concept like "beauty". It offers little practical guidance, although quality will be known when it is seen (Pirsig 1974).

According to the product-based approach, quality is considered to be a precise and measurable variable. Differences in quality are reflected by differences in the quantity of some ingredient or attribute possessed by a product. Quality is then defined as: "Differences in quality amount to differences in the quantity of some desired ingredient or attribute" (Abbott 1955).

According to the user-based approach quality depends on how well a product fits patterns of consumer preferences (Kuehn and Day 1962). Products that best satisfy the needs of consumers are considered to have the highest quality. This is a view of quality which is highly subjective. It will be difficult to distinguish between products with quality and products that just maximize consumer satisfaction. In this approach a much used definition is: "Quality consists of the capacity to satisfy wants" (Edwards 1968). Another even better known definition comes from the well known quality control expert Juran: "Quality is fitness for use" (Juran 1974).

According to the manufacturing-based approach the focus is on engineering and manufacturing practices. Deviation from the design means a reduction in quality. Quality is therefore defined as "Conformance to requirements" (Crosby 1979). Another much used definition is: "Quality is the degree to which a specific product conforms to a design or specification" (Gilmore 1974).

The value-based approach defines quality in terms of costs and prices. Quality means best for certain customer conditions. These conditions are the actual use and 
the selling price of the product (Feigenbaum 1961). This approach is of little practical guidance because two different concepts are used together: excellence and the price of a good. The result is "affordable excellence" and this is a concept that is subjective and lacks well-defined limits.

\section{The quality of total-joint replacement}

Although the manufacturers and the consumers (orthopedic surgeons) of joint prostheses will not normally be aware of this 'body of knowledge' in the literature, their actions and decisions are easily explained in the light of these definitions. A commercially successful prosthesis will have a transcendent quality for surgeons- "it looks right"- - or would not be sold. It will also have a high product quality, in the sense of highquality materials, and features which are generally assumed to be desirable, such as, for example, a coating for bone ingrowth or a surgical technique which enables efficient implantation. It will be a product that satisfies the needs of many surgeons, at least it will be perceived as such (user-based quality). The manufacturer will be most concerned about the manufacturingbased quality-"conformance to design and specification"- - but the surgeon will at least have confidence in the manufacturer's reputation in this matter. And finally, many will assume that expensive is good (valuebased quality), or at least that cheap can not be good. Probably, most sensible surgeons will decide based on a combination of the product quality-considering the quality of materials and design features that are assumed or reported to be desirable-and the user quality, which satisfies their needs, which can probably be summarized as easy to implant and the expectation of satisfied patients, who live happily ever after.

It is interesting to note, however, that while the orthopedic companies and the surgeons may have a pure manufacturer-consumer relationship relative to joint prostheses, the patient and the community at large are not so much interested in the quality of the prosthesis, but rather in the quality of the joint replacement, which is determined by more factors than just the characteristics of the prosthesis. Hence, it is the medical service that counts, not just the device. These factors include proper diagnosis, preparation and instruction, operation, hospital care, after care and follow-up. To assess the quality of the service, patients will apply the user-based approach; that is to say, judge it relative to their own needs, which are, indeed, to live happily ever after. More precisely, their needs are to be able to live a normal life, without pain, whereas the risks for death or serious disability caused by the cure should be at an acceptable level.

\section{Implant life cycle}

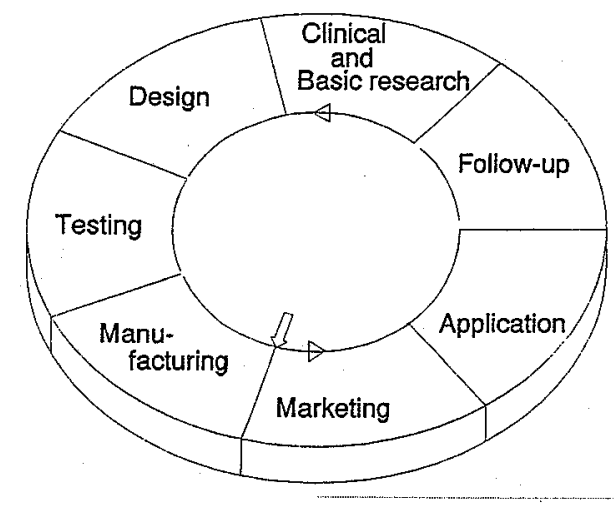

Figure 1. The life cycle model.

According to Sinha and Willborn (1985), “...quality is the totality of all characteristics of a product or a service as specified, required and expected". If we consider this general definition in terms of the patient needs, listed above, its vagueness becomes obvious. Without objective references for requirements and expectations such as 'normal life', 'without pain' and 'acceptable risk', a rational approach to the assessment of quality is impossible. Hence, standards of some form are necessary for any system of quality assurance. The standards should apply to the service of total joint replacements, not just the prosthesis. Obviously, since the prosthesis is an integral part of the service, its characteristics should also be subject to standards, applicable in preclinical and clinical trials. However, quality assurance of the prosthesis alone can not guarantee quality of joint replacement as a medical service.

\section{The life cycle model}

In the previous sections we have seen that the problem of quality assurance for human joint replacement is now more complex than just the question of how and when innovative prosthetic products should be marketed, a question predominant in the pioneer years. To put the relevant factors into perspective in this study, we used a conceptual model, the so called "life cycle model" (Figure 1), in order to clarify complex characteristics of both product- and service quality and to facilitate standardization. This implant- or prosthesislife cycle model is not to be confused with the 'product life cycle' concept as it is used in the marketing literature (Cox 1967, Dhalla and Yuspeh 1976). The life cycle model is a model that illustrates the implant's progress through time. Hence, a time aspect is incorpo- 
rated. Several stages in this life cycle may be distinguished: basic and clinical research, design, testing, manufacturing, marketing, application and follow-up.

The "life" of an implant starts with its first concept. The concept must be tested and only when the concept has shown to be a promising one the prosthesis should be manufactured and marketed. The design should prove itself during application. Conformance to the specified requirements must be shown through longterm follow-up of patients with an implanted prosthesis. Follow-up results must be analyzed in the research stage and the resulting information can be used to conceptualize a new design or to adjust the old design. The life cycle of an individual implant is discontinued by its removal from the patient's body. However, the information on the implant will flow to the following stage, "basic and clinical research", and can eventually be used to improve design characteristics. Hence, the life cycle model reflects an iterative process through which the original concept of a prosthesis moves. In the course of this process the concept is adjusted or abandoned in accordance with the long-term follow-up results. The objective will also be to improve upon the original concept and design. Hence, the result of the process will, hopefully, be a better, a higher quality, prosthesis.

The life cycle model will be helpful in illustrating at what time particular quality characteristics (either product-, surgeon-, or patient-related) are relevant. In the stages of the life cycle, basic and clinical research, design, testing,-manufacturing, and marketing, product quality characteristics are emphasized (Figure 1). In the application and follow-up stages, the surgeon-patient relationship becomes important. After that moment, we speak of the quality of the joint replacement procedure.

In summary, the concept "quality of total joint replacement" is determined by a variety of quality characteristics. Some of these characteristicss are implantrelated (design, materials), some are surgeon-related (skills and technical expertise) and others are patientrelated (physical condition, age, level of activities):

\begin{tabular}{l|l} 
Total joint replacement \\
quality determinants
\end{tabular}$-\left[\begin{array}{l}\text { Implant } \\
\text { Operating surgeon } \\
\text { Patient }\end{array}\right.$

\section{Quality assurance and the law}

The failures and disasters discussed in a previous section suggest that frequently prosthesis "make the life cycle too quickly", by being already used on a wide scale before the results of long-term follow-up studies became known. This naturally prompts the question whether the "life cycle" should not be put under some kind of "surveillance" by an objective external institution, e.g. the government. In the drug area, every new drug must have government approval before it is allowed on the market. In this area, already in an early stage, government authorities realized they had a responsibility to protect the general public against innocuous products. A major trigger to legislation in many countries was the thalidomide disaster. For example in the United Kingdom, the thalidomide disaster is sometimes called "the foundation stone" on which the Medicines Act was built (Griffin 1989). The disastrous effects of this sleep-inducing drug on children, whose mother had taken the drug during pregnancy, became obvious between 1959 and 1961. Not only in Great Britain, but in many other western countries as well, thalidomide was at the basis of many changes in drugs legislation.

Although the joint replacement field had its own disasters, these were apparently not serious enough-indeed, not "life threatening"-to initiate regulation in all countries. In countries that do have medical device legislation enacted, it is generally the duty of the government to protect the public from unsafe or ineffective medical devices. As a rule, governments will try to realize this protection by way of legislation. As a consequence, this means interference with the life cycle of the device. If the government interferes in this process, as happens for instance in the United States, it actually means that in the life cycle process, conditions will be put on the different stages. For example, an obligatory clinical research stage might be built in before permission can be obtained to apply the prosthesis in daily practice.

Besides the benefits of protective regulation, these government actions entail, in most cases, loss of time and expenses for the manufacturer. In addition, it may create a conflict between protection of the general public against unsafe and ineffective developments, on the one hand, and denying them positive developments on the other. Hence, innovation may suffer and development becomes more expensive.

In the American literature, studies may be found in which a negative correlation between the measure of a biomedical firm being innovative and the firm's economical success is demonstrated (Hauptman and Roberts 1987). These results are found only in this province, everywhere else this correlation is positive: innovation leads to economical success. The reason for this is the fact that biomedical firms are often small and not very strong economically. The innovation process is expensive. The same counts for meeting all the stat- 
utory requirements. It is important to create an equilibrium between the costs of regulation and the benefits. Unfortunately, this equilibrium is not always present, as will be shown in the next chapter.

\section{Summary and conclusions}

We have seen that quality can be regarded from many different perspectives and that the 'consumers' of prosthetic devices (the surgeons) may approach quality by weighing different kind of factors. However, the quality of a joint replacement is dependent on more parameters than the prosthesis alone. Quality assurance should be a concern from the perspective of the patient, and quality of a prosthesis is of importance only insofar as it enables the surgeon to satisfy the requirements of the patients. In order to assure quality in this sense, the prosthesis, the implantation procedure, and anything else related to the medical service provided, should "conform to requirements", which can only be materialized by the introduction of standards.
We have also seen that although scientific, clinical and technological tools offer the possibilities for the developments and application of standards, some kind of regulation mechanism is needed to assure their consistent enactment by manufacturers and surgeons at large. As argued, however, any regulatory mechanism introduces bureaucracy, higher costs of developments and longer routes from innovative products to the patients, in addition to higher costs for the community at large. Hence, regulatory mechanisms are-and should be-subject to cost-to-benefit considerations and balances.

In this light, the government regulation systems existing in a number of countries are investigated in the next chapter. Particularly emphasized are the questions whether they create reasonable cost-to-benefit relationships and whether the fact that the quality of joint replacement in total should be regulated rather than the quality of the prosthesis alone, is properly recognized in the legislation. For this purpose, the life cycle model is applied in the analysis. 


\section{Total joint replacement and the law}

\begin{abstract}
"I am not an advocate for frequent changes in laws and constitutions. But laws and institutions must go hand in hand with the progress of the human mind as that becomes more developed. More enlightened as new discoveries are made, new truths discovered and manners and opinions change. With the change of circumstances, institutions must advance also to keep pace with the times. We might as well require a man to wear still the coat which fitted him when a boy as civilized society to remain ever under the regimen of their barbarous ancestors."

(Thomas Jefferson, 1743-1826)
\end{abstract}

In this chapter an analysis is presented of the different legal quality control requirements in the United States and Europe. What we will see is a variety of standards and requirements, and differences in drafting and enforcement of these standards. The question whether these systems are an impediment to innovation, whether they go "hand in hand with the progress of the human mind," will be hard to answer. The objective of law systems should be to create a balance between the "costs" of regulation and the benefits, protection of public health. In this chapter we will consider whether "the coat still fits."

\section{The United States of America}

\section{Introduction: the system of the Medical Device Amendments}

In the USA, safety and effectiveness of medical devices have been public responsibilities since the early 1970s. Up to 1976, the Federal Food and Drug Administration (FDA) had only a few regulations from the Federal Food, Drug and Cosmetic Act from 1938 at its disposal that could be used against unsafe devices. However, only after the damage had been done ("after the fact regulation"). In the 1970 s, a period in which many decrees were issued for the purpose of "consumer-protection", it was thought necessary to change this situation. In 1976 the Medical Devices. Amendments were introduced, and since that time the FDA has ample measures to deal with the matter at its disposal. The introduction of the Amendments presented a tremendous challenge for the FDA. The Act concerned about 1800 different types of medical devices, brought on the market by some 7000 manufacturers and distributors. Altogether there are about 41,000 products the FDA has to supervise, varying from "bedpans to brainscans" (Staff of House Subcommittee on Oversight and Investigations of the House Committee on Energy and Commerce 1983). The Amendments are generally considered as "complex legislation negotiated by lawyers for lawyers" (Munsey and Samuel 1984).

\section{The system of the Medical Device Amendments}

On the basis of the Medical Device Amendments, the FDA is competent to issue regulations (Medical Device Amendments of 1976). There are three classes in total, each subject to a different kind of government regulation. The rules will be more stringent relative to the risk the use of the device induces.

\section{Class I: "General Controls"}

In this class those devices are classified for which a minimum of regulation is sufficient to guarantee safety and effectiveness, like gauzes, bedpans, crutches and wheelchairs.

"General Controls" include, amongst others, the following measures:

- "Adulteration or misbranding"

A device may be taken off the market when it is suspected that it may have caused damage.

- "Registration and listing"

It is an obligation for all manufacturers to have their companies and their products registered by the FDA. This obligation applies also to distributors who import medical devices. If a manufacturer plans to market a new product, the FDA has to be notified 90 days in advance.

- "Good Manufacturing Practices" (GMP's)

These obligations relate to manufacturing, packing, storing and installing a device. This "GMP" measure implies control by the FDA. Controls must take place at least every two years and are more rigorous when the potential risk of the product is higher (so called "critical devices").

- Obligation to keep files and to submit reports The manufaciurer must keep files on the manufacturing process, which will be inspected by the FDA.

These tequirements apply to all classes of medical devices. Regarding class I devices, they are the only requirements which are applicable. 


\section{Class II: "Performance Standards"}

In this class those devices are classified for which "General Controls" do not offer sufficient guarantees as far as safety and effectiveness are concerned, like hearing aids, bone plates, and catheters. "Performance Standards" relate to preestablished specifications regarding the manufacturing and functioning (performance) of the device.

\section{Class III: "Pre market approval"}

Devices put in this class may be introduced on the market only with the permission of the FDA ("pre market approval"). Only the most risky devices are put in this class. A class III device is a device that "supports or sustains human life or is of substantial importance in preventing impairment of human health or presents a potential, unreasonable risk of illness or injury." Pacemakers and artificial heart valves are examples of class III devices.

Obtaining "pre market approval" (PMA) for a class III device implies that proof has to be submitted that the device is safe and effective. The burden of proof lies with the applicant. A class III device which does not satisfy the PMA requirements is "adulterated" and is not allowed on the market.

Of great importance is the date on which the Amendments took effect, May 28, 1976. The FDA distinguishes devices marketed before that date ("pre amendments devices") and those introduced after that date ("post amendments devices"). Devices classified as drugs before May 28,1976 , are automatically put in class III. In that case, a PMA is required for the product in order to keep it on the market. Examples of these "transitional devices" are bone cement, lenses and surgical sutures.

Soon after the enactment of the Medical Device Amendments in 1976 it became clear that the major part of all medical devices would be classified into class II. As a consequence, a tremendous amount of performance standards had to be drafted. However, since 1976, in fact only one performance standard has been drafted. For that reason the usefulness and necessity of "performance standards" for class II devices have been topics of discussion ever since the enactment of the Medical Device Amendments.

\section{The Amendments relative to total joint prostheses}

\section{Market approval of joint prostheses}

Because of the registration and listing obligation, manufacturers have to notify the FDA when they intend to bring a medical device on the market (the so-called "pre market notification provision", Sec.510(k) of the
Medical Device Amendments). Thereupon the FDA will consider whether the notified device is "substantial equivalent" to a pre amendments device or a device already on the market. It is not precisely defined in the Amendments what the term "substantial equivalence" implies. If a strict interpretation is used, every device that in any way deviates regarding materials, design or otherwise, would not be substantially equivalent. With a less strict interpretation, only changes fundamentally influencing the safety and effectiveness of the device have to be considered. The conclusion "substantial equivalence" is no proof for safety and effectiveness, but solely a statement that the device in question is not less safe or effective than a similar pre-amendments device. If "substantial equivalence" is accepted, the device is directly admitted to the market. If that is not the case, classification in class III follows automatically and the device is submitted to a PMA procedure, unless a request for reclassification to class II or $I$ is met. Pre market approval implies that the safety and effectiveness of "new" (hence, class III) and all "post amendments class III" devices have to be proven. This must be done on the basis of "valid scientific evidence". As a consequence, clinical trials will have to be carried out with the device.

At the end of 1983, the FDA had received a total of 24,213 premarket notifications (the so called "510(k)'s") and only 358 PMA applications. In 1988 the total number of devices and modified devices that had been brought on the market since 1976 by way of the $510(\mathrm{k})$ procedure amounted to 34,000 . Regarding the PMA procedure that number is about 2,200. The $510(\mathrm{k})$ procedure is a fast route to the market because in principle no clinical data have to be submitted, exclusively data regarding the conformity with a device that is already on the market. The FDA has been criticized by consumer representatives because of the widespread use of the $510(\mathrm{k})$ route to the market. In this way a lot of possibly "dangerous" products would be allowed on the market without sufficient proof of their safety and effectiveness (Kahan 1986).

Hence, if a manufacturer wants to bring a new type of prosthesis on the market, he will submit a "pre market notification"to the FDA and start a $510(\mathrm{k})$ procedure. The quickest way to get admission to the market is to supply proof, together with this "pre market notification", about the "substantial equivalence" of the new prosthesis with a "pre amendments" prosthesis which is already on the market, or with a prosthesis which was reclassified to class II. In 1989, the FDA for instance, referring to the reclassification of the "hip joint metal/ceramic/polymer semi- constrained cemented or noncemented prosthesis", issued a guidance document, to indicate how a pre market notification should be sub- 
mitted for these so called "ceramic ball hip systems" (FDA Guidance 1989).

If "substantial equivalence" can not be proven, the prosthesis is classified in class III and a "pre market approval" will be obligatory. The manufacturer must then prove safety and effectiveness of the prosthesis. The FDA decides not before valid, scientifically obtained proof about safety and effectiveness is available. This means in general that in addition to in vitro tests and animal experimentation, properly organized clinical trials must be conducted. The trial protocols are submitted for approval by the FDA, which may then issue a so-called "Investigational Device Exemption" (IDE). The essence of the IDE regulation is that the "sponsor" of a new device submits a request to experiment with the device. A "sponsor" is a person or a company, initiating the experiment and carrying the final responsibility. Important requirements are the participant's (patient's) informed consent and that detailed files are kept about the progress of the experiment. To obtain an $\mathrm{DE}$, several documents must be submitted: the research protocol (including the "consent forms") and a list of participating, well qualified researchers.

After concluding the clinical trials, the official PMAapplication will be filed with the FDA. Upon evaluating this PMA-application, the FDA consults the "Orthopaedic and Rehabilitation Devices Panel". This panel comprises of orthopedic surgeons and other experts in the orthopedic field. A PMA procedure may take much time, as becomes evident from the following example: in 1982 the FDA allowed a manufacturer to do clinical studies (according to an "IDE") with a certain type of porous coated prosthesis (FDA Zimmer USA 1989). In January 1988, the PMA application was approved by the Panel on the basis of the results of all the tests and one year later approval was given by the FDA. Hence, the prosthesis was admitted on the market seven years after the first step on the route to the market.

\section{Criticism on the Medical Device Amendments}

During the first six years after enactment of the Amendments, it was left to the FDA to implement the regulations. In 1982, Congress began to worry about the progress. This resulted in a number of Hearings in which the performance of the FDA was discussed. In an evaluation survey about the implementation of the Amendments, carried out by a Committee of the Congress, it was stated that "the real problem of the medical device regulatory process is the problem of delay and its consequences on the ability of business to compete fairly and successfully (FDA 1983). In partic- ular, much criticism arose about the IDE-rule. Especially the medical profession feared that the regulation would be a barrier to innovation: "Regulation and innovation are mutually contradictory terms and there is no question that innovation will suffer" (Dobelle 1977). A bad example was set in the drugfield: strict regulation had a strong negative influence on the development of new drugs and led to a so-called "drug lag."

Another criticism was that about many pre amendments devices proof about safety and effectiveness had never been required. Much of the criticism regarded problems of which the existence was already known at the FDA. However, it has been difficult to decide to which extent public health is endangered by the gaps in the regulation and it will be hard to find the right solution. It is important that the FDA disposes over enough means and the authority to implement the Amendments. The work-load associated with implementation of the Amendments is much larger than could ever have been foreseen.

In 1986, 10 years after the enactment of the Amendments, the first proposal to improve a number of regulations was introduced in Congress. This "Bill" received insufficient support. Eventually, in November 1990 the "Safe Medical Devices Act of 1990" was signed into law (Safe Medical Devices Act of 1990, 1990). This act comprises many important changes. The new law is the first major revision of the Medical Device Amendments of 1976. It is the result of four years of effort by in particular Congressman Henry Waxman, D-CA, Chairman of the Subcommittee on Health and the Environment of the Committee on Energy and Commerce of the US House of Representatives. Significant new provisions relate to user and distributor reports of problems with medical devices, device tracking systems, the issue of pre amendments class III devices, performance standards, post marketing surveillance, recall authority and civil penalties. Another new requirement is that the FDA may include a preproduction design validation in the already existing GMP provisions. This provision is an equivalent of a requirement in the future European Community Directives for medical devices.

Relative to joint prostheses, the obligation of design validation in the pre clinical testing stage and an obligation for the manufacturer to organize a "tracking" system for his devices are important. Regarding implants this means that patient registrations will have to be kept. 


\section{France}

\section{Market approval ("homologation") of medical devices in general}

Since 1982, the so-called "homologation" (market approval) system for medical devices has been enacted in France (Arrêté du 9 décembre 1982). Devices subject to this regulation are mentioned limitatively in a decree of May 23, 1984 (Arrêté du 23 Mai 1984). There are 5 main categories of products:

- Image forming (e.g. ultra sound);

- Surgery and therapy (e.g. lasers and electro-surgical equipment);

- Materials to support the functioning of the human body, (for instance joint prostheses, dialysis-equipment and blood-pumps);

- Anaesthesia and intensive care equipment;

- Monitoring and cardiology equipment.

For each of the 5 categories, a subcommittee is established with the task to advise the "Commission Nationale d'Homologation" regarding the homologation of a particular device. These subcommittees are comprised of physicians, engineers and representatives from the public administration; manufacturers are excluded (Ministère de la Solidarité, de la Santé et de la Protection Sociale, 1985).

In the category implants, in particular pacemakers, implantable infusion pumps, catheters and joint prostheses are subject to the homologation regulation.

The homologation is finally granted by the Secretary of Public Health. This occurs on the basis of the results of two types of tests: technical tests and clinical tests. The technical tests must prove that the device satisfies specific safety standards. If no standards for the device exist, a special test-protocol is drafted, by so-called "groupes de travail" (task forces). These task forces are comprised of physicians, engineers, representatives from the public administration and manufacturers. Other than in the subcommittees, manufacturers do take part in these deliberations.

If the technical tests prove that the device is safe, it still has to be tested clinically. This means that it has to be shown that the device conforms to the purpose for which the manufacturer of the device has intended it ("intended use"). These tests also take place on the basis of a protocol drawn up by the task force for that purpose, in two assigned hospitals.

After four years working with the homologation system, the conclusion was drawn that particulariy clinical testing proved to be useful and a necessary prerequisite to establish a device's safety. Conformity to only technical standards does not offer sufficient guarantees for safety (Commission Nationale d'Homologation 1987). In principle, homologation means that public (government) hospitals are allowed to purchase only those devices that have successfully passed the tests or are in the process of receiving homologation. The intention is to apply this regulation also to private hospitals in the future. A proposal to amend the law is submitted to the EC Commission (every new national regulation that possibly could imply a new trade-barrier has to be announced and approved by the European Community Commission, this concerns the so-called "stand-still" regulation). The list of the devices subject to the homologation regulation is regularly supplemented. These extensions also have to be approved by the European Community Commission.

In addition to the homologation-procedure, which mainly concerns the product, the manufacturer may also have his production-method certified on a voluntary basis. This so-called "QUALIMECA" certificate is given after inspection by an institute (CERTIMECA) which is assigned for that purpose by the Department of Trade (Christel 1989). The qualification obtained in this way entitles the manufacturer to put the "NF" (Norme Française)-sign on his products. The manufacturer benefits because of this voluntary quality-control; during the homologation-procedure fewer testing-obligations will be required for his products.

In 1986, a system of medical device problem reporting was organized in France. By way of a departmental circular, all public hospitals were announced that important incidents, in which medical devices were involved, had to be reported centrally. Up to February 1989, 88 reports had been received in all. The number of reports was evenly spread over the years and more than half of the reports concerned accidents with a device from the category "anesthetic-intensive care".

In conclusion, the French system of quality-guarantee for medical devices consists of two (main) parts:

- Homologation of the product (obligatory for designated devices);

- Certification of the manufacturer (voluntary).

\section{The market approval ("homologation") of joint prostheses}

\section{General}

On October 1, 1987, the homologation obligation for joint-prostheses took effect (Arrêté du 24 Fevrier 1987). The "Sous-Commission' Suppléance Fonctionnelle Orthopédique" was set up and was charged with the task to actually organize the homologation. This subcommittee is comprised of orthopedic surgeons, engineers and government representatives. This subcommittee formed a task force, "Prothèses Articulaires," which for two years has worked on the (above mentioned) test-protocols for hip prostheses. 
First they were occupied with the homologation of hip prostheses. In 1991, 526 prostheses had been presented for homologation, originating from 21 distributors. Up till August 1991, about 50 prostheses had been homologated, about ten had been refused (Personal communication, Ministère des Affaires Sociales et de l'Intégration, Ministère délegué à la Santé, Direction des Hopitaux). The subcommittee expected that about 100 prostheses would have been approved before 1992 . According to article 3 of the applicable "Arrêté" (decree), manufacturers are allowed to proceed with selling prostheses already on the market, provided homologation has been applied for before March 31, 1988.

Considering the fact that there is only little experience with this procedure, it is difficult to draw conclusions about its effectiveness. Hence, the contents and procedures of this system will only be discussed in a conceptual sense.

The main objective of the homologation procedure is to establish the safety of an implant, as far as possible (Ministère de la Solidarité, de la Santé en de la Protection Sociale, 1988). This procedure should also have an educational effect by making orthopedic surgeons aware of the specific properties of a certain prosthesis (Sedel 1987). Homologation applies to total hip prostheses, that is prostheses comprising of both a femoral and an acetabular part. Homologation is requested for a "famille" (family) of prostheses. "Famille" means a group of prostheses bearing the same commercial brand, which are based on the same principles. Every "famille" can consist of multiple series, every series again consists of all the sizes of the same model. The manufacturer submits a request for homologation. This is done by way of submitting various files:

- A file regarding the manufacturer's company, inciuding a certification of the company (QUALIMECA), if available;

- A file with regard to the product. The most important document in this file is the "bulletin d'identification" of the prosthesis in question, including all specifications;

- A technical file;

- A clinical file.

The technical file is drawn up on the basis of data obtained from a series of technical tests. Per type of prosthesis a sample of three prostheses is taken to be tested. These three are tested in the "Laboratoire Nationale d'Essai". If the manufacturer has the QUALIMECA qualification, only one prosthesis is tested by the Laboratoire Nationale. In that case the manufacturer, with respect to the remaining two, may submit his own test results. The tests concern the chemical-physi- cal, the mechanical and histomorphological (biological) characteristics of the prosthesis.

The clinical file is composed on the basis of the results of the clinical trials, in general carried out in two different hospitals. These centers are proposed by the manufacturer and must be endorsed by the subcommittee. The centers must be chosen out of a list drawn up by the Department of Health, especially for this purpose. Clinical trials are only allowed to be carried out by centers which employ members of the French orthopedic association (Christel 1989).

The files will have to prove that the prosthesis meets certain criteria. The subcommittee decides on the results of the tests. Next, the subcommittee submits a homologation proposal to the "Commission Nationale d'Homologation" which ultimately grants or rejects homologation. The homologation is always granted for a maximum of 5 years, but may be renewed after that time.

\section{Classification of the prostheses}

The application for a particular class is done by the manufacturer himself. The subcommittee has the responsibility to assess the application for a certain class. The subcommittee differentiates between 5 classes of prostheses, with the following characteristics:

- Original prostheses. The first implantation dates back to over 5 years, counting from the date of the homologation-application and the number of "in succession implanted and followed-up" prostheses is greater or equal to 50 within one institution (i.e. a group of absolutely identical prostheses, implanted inside a specified institution and during a specified period in patients that are regularly checked during a specified period).

- Identical prostheses. These prostheses are identical to original prostheses, yet they are manufactured by a different manufacturer and the first implantation dates back to less than 5 years.

- Modified prostheses. This class refers to "original" prostheses that have been modified, the modification can apply to the geometry, materials used or the manufacturing process.

- Innovative prostheses. These prostheses are "new" with regard to the materials or design

- Special prostheses. These prostheses may only be implanted upon application, with a special medical file and after official permission. The number of implants will always be less than ten per year.

\section{Original prostheses}

The homologation can be granted on the basis of proof produced in three files: an administrative file, files applying to the product and a clinical file. The product 
file consists of all specifications with respect to the prosthesis. The prosthesis has to be technically examined. This is done in accordance with a protocol drawn up by the task force "Prothèses Articulaires".

The clinical file consists of 3 parts:

- Publications in scientific journals;

- A report from the manufacturer regarding institutions having performed more than 50 implantations;

- A completed questionnaire regarding the performance of the prosthesis. After selection and approval of two institutions, enquiries are made about 50 implantations of the prosthesis. This means that the surgeon must complete a questionnaire which is entered into the file. This concerns information about the use of the prosthesis and the results of follow-up studies.

\section{Identical prostheses}

When it is established that the prosthesis is identical to an original prosthesis ("prothèse de référence"), data regarding this original prosthesis may be used to apply for homologation. The clinical and the product files will have to be composed of the-same type of data as regarding an original prosthesis. However, in this category a second clinical phase is built in: in two institutions a prospective clinical evaluation (trial) will have to be started. The homologation will initially be granted for two years. An extension of three years can be granted until a clinical file is compiled, as is the case with the original prosthesis. Another obligation is that during the trial period, on the label of the prosthesis mention has to be made that the prosthesis is still in the process of homologation.

\section{Modified prostheses}

The procedure to be followed and the type of data to be gathered, are similar to the procedure for an original prosthesis and, with regard to the second clinical phase, similar to the procedure for the identical prosthesis. The only difference is that one has to indicate on which points the prosthesis differs from the original one. Depending on these differences, the subcommittee may require supplementary information. It is important whether the manufacturer himself has obtained homologation of the reference-prosthesis or not.

\section{Innovative prostheses}

The procedure that has to be followed is similar to the procedure regarding the original and the identical prostheses. The only difference is that the subcommittee has to approve the test protocols before clinical trials may be started. Moreover, a special file ("dossier innovation") has to be submitted. In this file the specific innovative aspects of the prosthesis are considered.
Depending on the results of the tests and upon proposal of the subcommittee, homologation may be granted for two years. This is done with the following three obligations:

- A special label has to be fixed to the prosthesis, on which it is mentioned that the prosthesis is still in the homologation phase;

- The subcommittee must be informed systematically about all problems occurring with the prosthesis;

- Ultimately, a clinical file has to be compiled similar to the clinical file with regard to an identical prosthesis.

After 2 years the homologation may be extended until the clinical file has been completed, or the homologation may be rejected. When a period of 5 years has expired after the first homologation request, the clinical file is reviewed and finally a decision will be made.

\section{Special prostheses}

Every year the manufacturer has to state how many prostheses of this type were sold. If the number exceeds ten, a normal homologation procedure has to be started. The same files will have to be submitted as is the case for an original prosthesis.

\section{Discussion of the French system}

It is clear that the procedure is very time-consuming, for the manufacturer, as well as for the subcommittee. There is a risk that the procedure will retard the marketing of new prostheses. Although there is awareness of this and it is tried to prevent this from happening, the procedure does not proceed very rapidly. Untill now, only a limited number of hip prostheses has been homologated.

The influence of "field-experts" is of great importance because of the fact that in the procedure both the subcommittee and the task force play a central role. The task force drafts the test protocols. The subcommittee takes a decision about the classification of the prosthesis, examines the files and makes a final proposal for homologation. In this way practical expertise is directly introduced into decision- making. This happens in a different way from the American system, where the Advisory Panel of experts does not play a direct role but only advises the FDA, which drafts and approves test protocols and decides itself.

At this moment it is still too early to draw conclusions regarding the effectiveness, that is to say: does the system improve quality? However, in any case the question which prosthesis is still in an experimental stage and which is not, is clarified in this system. When a prosthesis is still in the homologation phase, this has to be marked on the prosthesis itself. Within the proce- 
dure, the 5 years term is essential. This is a reasonable period of time to get a good idea about the performance of the prosthesis.

\section{The Netherlands}

\section{Introduction: The Dutch Medical Devices Act}

In 1959, the Health Council of the Netherlands was required to advise if "it would be possible and desirable" to subject the quality of medical devices to governmental regulation. In 1963 this question was answered in the affirmative and even "urgency for setting up surveillance" for certain devices was mentioned (Gezondheidsraad 1963). Implantable metal devices were especially mentioned in this respect. However, the enactment of the "Medical Devices Act" only took place in 1970, hence seven years later (Wet van 15 januari 1970). The objective of the Act is to facilitate regulatory activities with two objectives: to guarantee the quality of medical devices and to promote their safe use.

The Act is a so-called "framework act": the matter is regulated only in broad outline, the elaboration is left to the Crown or to the Secretary. The intention of a law like this one is to promulgate decrees in a fast and efficient way, or to adjust them, without having to change the law itself. The Medical Devices Act offers only a general framework with regard to exercising supervision. For every device, quality control may be ordered by decree, if considered necessary. Notwithstanding government's and Parliament's intention, or the Health Council's recommendation in 1963, it in fact never came to implementation of the law by way of decrees, as originally intended (Faro 1986).

\section{Problems with the implementation of the Act}

As mentioned above, the actual implementation of the Act had to be done by drafting a number of decrees regarding specific types of devices. In 1978, quality control of rubber condoms was regulated by way of decree, and in 1982 and 1983 decrees followed dealing with trade and use of sterilized medical devices. Statutory regulations regarding implants as mentioned by the Health Council in 1963 failed to be drafted. In fact the Act has not been made operational, contrarily to the original intentions.

A number of factors have contributed to this situation (Faro 1990). Because of the great diversity and scope of the matter to be regulated, there has been a continuous fear of the amount of regulations necessary in order to implement the Act. The fact that many medical devices are subject to continuous changes implies that regulatory requirements must be adapted quickly in order to implement these changes. Even if this is done by decree, it will be difficult to keep up with innovation. Also "deregulation" (the policy of the withdrawal of the government as a regulator) as a general problem of government regulation has influenced the implementation of the Medical Devices Act. "Deregulation" is in sharp contrast with the system of a framework act with specific regulations by decree.

At European Community level directives are drafted which will eventually have to be incorporated in the Dutch legislation, as we will see in the next section. Consequently, an attitude of "wait and see" has been adapted in the Netherlands. In principle, this conforms to the basic requirements of the European Community Treaty (new legislation in the member states is only allowed after approval of the European Community Commission). However, it is in sharp contrast with the situation in France, as described above.

\section{Market approval of joint prostheses in the Netherlands}

With regard to orthopedic implants, the government has not been able to arrive at any policy at all. The question may be posed whether patient protection against unsafe prostheses is adequately taken care of by the government. In the implant life cycle, the transition from the manufacturing to the marketing stage is not subject to any regulation at all. As a consequence, there is no clear distinction between "experimental" and "conventional" prostheses. In the past this has caused prostheses to pass the life cycle too quickly (for instance Wagnerand Mittelmeierprostheses). The risk that this will happen again is still present in the Netherlands. There and above, there is a possibility that new prostheses, developed elsewhere in a country in which the research stage is strictly regulated, are tested for the first time in vivo in the Netherlands. Presently it is not possible to prevent this from happening. With regard to the minimal level of patient protection provided by the law in the Netherlands, this situation may endanger the safety of orthopedic patients in a serious way.

\section{The United Kingdom}

Before we give an impression of the British system, we will briefly indicate how the British Health Care System works. In the United Kingdom, every citizen is 
insured in principle for health care through the National Health Service. The Department of Health and Social Security (DHSS) supervises about 1900 hospitals. The financial management as well as the quality assurance procedures of these National Health Service are the responsibility of DHSS (Duncan 1987). As a consequence, the DHSS is the most important customer of the medical devices industry. Annually the amount of about 4 billion pound Sterling is spent on hospital goods and services (Donawa 1992).

The quality assurance of medical devices is DHSS' responsibility as well. The most important part of this policy is the so-called "Manufacturer Registration Scheme". This registration of manufacturers has been started in 1982 and contains the names of approximately 500 manufacturers. These manufacturers all comply with the United Kingdom quality system guides (Donawa 1992). Objective of this registration is to supervise and check the quality of the manufacturing process through the drafting of standards and implementation of inspections. In order to be registered, a manufacturer has to state that he manufactures in conformity with the applicable "Guides to Good Manufacturing Practices (GMP)" that have been drawn up by the DHSS (DHSS 1988). Originally, there were four GMP guides, which have recently been replaced by new guides consisting of the ISO 9000/EN 29000 series of standards (Donowa 1992). When no applicable GMP exists for the device in question, there must be conformance with the relevant part of "British Standard 5750: Quality Systems". A manufacturer is only registered when an inspection by DHSS has proved that there is conformance with the GMP or a "Standard".

The registration is valid for a period of three years in principle. If it becomes clear that the conditions are no longer met, the registration may be canceled by DHSS. Participation by the manufacturer in the registration is voluntary. However, National Health Service hospitals are strongly advised to procure exclusively - devices from a registered manufacturer. As a consequence, the registration implies that "If you are not in it, you don't sell" (DHSS 1988).

In 1984, a "Good Manufacturing Practice for Orthopaedic Implants" (the so-called "Gold Guide") was drawn up by DHSS in cooperation with the United Kingdom Trade Associations (Higson 1986). In this GMP, specific requirements regarding the quality assurance system for orthopedic-implant manufacturers have been detailed. This system regards principally the manufacturing process, but contains also requirements with regard to design validation. Sect. $4.8(\mathrm{~h})$ of the GMP requires evaluation of new materials under suitable environmental conditions. With regard to orthope- dic implants, the so-called "environmental conditions" should entail in vitro testing under full load, in contact with a chemically active environment, in vivo testing on animals and in clinical trials.

Except for a few medical devices regulated as drugs under the Medicines Act, there is no government regulation of devices in the United Kingdom. Most medical devices are controlled through the voluntary system as described above and through NHS procurement specifications and standards. The NHS constitutes $90 \%$ of United Kingdom buying power, meaning that compliance with these voluntary standards is a powerful incentive for manufacturers who are interested in the British health care market (Donawa 1992).

Besides these activities, there is also a device-incident reporting system in the United Kingdom.

\section{Germany}

In Germany the quality assurance government policy for medical devices is embodied in two different categories of requirements (Reinikainen 1987). The first category of requirements regards drugs. The concept "drug" as used in the "Arzneimittelgesetz" comprises "classic" drugs as well as a number of products which are medical devices. The last group includes, among others, sterile disposables, certain implants (like dental implants and xenografts), bone cement, sutures and in vitro diagnostics.

The second category of requirements regards primarily medical equipment. The most important regulation is the "Medizingeräteverordnung" which took effect January 1,1986 . In this last regulation, medical devices are classified in four groups:

Group 1. Active medical equipment, like defibrillators, infusion pumps, anaesthetic equipment;

Group 2. Active implants;

Group 3. Other active medical equipment not belonging to groups 1 or 2 ;

Group 4. All remaining equipment.

A premarket approval is only obligatory for the devices from groups 1 and 2 . These devices have to be tested by a "testing-institution" (so-called "Technischer Überwachungs-Verein"; TÜV). In this inspection the emphasis is on the equipment's safety and not so much on the "efficacy" (is it effective in curing the patient?). The testing is done relative to (mainly German; DN) standards.

The most important requirement for orthopedic implants concerns a notification duty to the authorities regarding the development, experimentation (clinical trials) and the introduction to the market of a new 
implant. There are also labelling instructions and the manufacturing process has to be in accordance with a Good Manufacturing Practice. In contrast with a "classic" drug, there is no real "pre market approval" for orthopedic implants.

\section{European Community directives}

\section{The common market}

Article 2 of the European Community Treaty describes the objectives of the European Economic Community as "harmonic development of the economic activity within the whole of the Community, a steady and balanced expansion, a greater stability, an increasing improvement of the standard of living and closer relations between the States united in the Community" (Treaty in order to institute the European Economic Community, signed in Rome, March 25, 1957). These objectives should be realized by "the institution of a common market and the gradually drawing nearer to each other of the economic policies of the MemberStates." In order to attain the objective of one common market, all barriers to trade should be abolished between the member states. The completion of the internal market is described more in detail in the "Single European Act" which came into force in July 1987 (European Act/Change of the Treaty of Rome, signed February 17 and 28, 1986). This treaty is an amendment to the Treaty of Rome (basis for the European Community: the European Community Treaty) and its goal is the accomplishment of the common market by December 31, 1992.

With the intention to expedite this common market, the European Commission published in June 1985 the "Paper regarding completion of the internal market by 1992". In this so called "White Paper," about 300 directives are mentioned which must be drafted before the end of 1992. A directive forms a part of Community legislation, is proposed by the Commission and adopted by the European Parliament and the Council of Ministers. Eventually, these directives will be transferred to the member states' law systems and replace national requirements. In this way, free movement of people, goods and services will be accomplished.

\section{The European normalization policy}

Free movement of goods will be realized through harmonization and normalization. In 1985 the European Community Council accepted a resolution regarding a new approach in the field of technical harmonization and normalization. In this resolution a policy was mapped out, the so-called "New Approach" (Council of the European Community 1985). This policy is based on a decision by the European Court in which it was decided that a product manufactured and marketed in accordance with the requirements of one member state, must be admitted in all other member states (Case "Cassis de Dijon," i.e. case 120/78, Rewe-Zentral AG vs Bundesmonopolverwaltung für Branntwein (1979) JUR 649). Medical devices are classified as industrial products and trade restrictions will have to be removed in the same way as with regard to other categories of industrial products. Hence, this "New Approach" will apply to medical devices as well.

The "New Approach" is based on the principle that harmonization will be limited to the adoption, by means of directives, of the most important safety requirements ("Essential Requirements") which products brought on the market will have to meet, in order to be allowed in free trade in the Community. Normalization institutions are assigned to draft technical specifications ("standards"). "CEN" (i.e. European normalization committee) and "CENELEC" (i.e. European Committee for electrotechnical normalization) are presently charged with the drafting of European standards. Trade and industry need these specifications in order to meet "Essential Requirements" as they are mentioned in the directives. However, these standards are not binding. The manufacturer may prove compliance of his products with the "Essential Requirements" either by referring to European standards, or in an other way as described in the directive.

\section{The European Community directives for medical devices}

Regulatory requirements regarding medical devices in the various member states tend to differ a lot. For a manufacturer, this means that his medical device has to meet a variety of requirements, depending on the country where he wants to market his device. This may apply, for instance, to different labeling-requirements, different registration-methods or different Good Manufacturing Practices. These different requirements are, in the sense of European Community law, "barriers to trade" and will have to be abolished. In order to do so, a harmonization policy is being drafted which will be adopted by all member states and replace the national requirements. As a consequence, eventually the same statutory poiicy wiil appiy in ali member states. The European Community policy for medical devices implies that after 1992 a device that is admitted to the market in one member state, will immediately have access in all other countries, without additional requirements. 
On a European Community level, four manufacturers' trade-organizations are involved in drafting three directives which will constitute this harmonized policy which has to be adopted by the member states before 1993: The International Association of Medical Prosthesis Manufacturers (IAPM) concerning the active implantable medical devices directive; the Coordination Committee of the Radiological and Electromedical Industries (COCIR) concerning a general medical devices directive; the European Confederation of Medical Suppliers Associations (EUCOMED) concerning a general medical devices directive; and the European Diagnostic Manufacturers Association (EDMA) concerning an in vitro diagnostic medical devices directive. The total area of medical devices is divided into three product groups; for each group a directive will be drafted. The directive regarding "active implantable electro-medical devices" (AIEMD) is the first one of these three, which, in draft, was accepted by the European Commission. The second directive covers all medical devices except electromedical implantable devices or in vitro diagnostics. An official Commission proposal was published in 1992 and will be discussed below. The third directive covers in vitro diagnostic devices. At this moment (November 1992) a draft for this directive is being discussed.

\section{The "European Community directive on medical devices"}

A final draft for a Council proposal for this directive was published in 1992 (Commission of the European Communities 1992). The directive will probably be accepted mid 1993. The directive applies to a variety of medical devices, including orthopedic implants. A general requirement is that medical devices placed on the market will not compromise the safety and health of patients, users and other persons when properly installed, maintained and used in accordance with their intended purpose. What safety means is explained in detail in the "Essential Requirements." Manufacturers must meet these requirements if they want to market their device. The requirements are technically specified in harmonized standards. As explained above, abiding to these standards is voluntary. This means that a manufacturer may prove compliance to the "Essential Requirements" by manufacturing in accordance with these standards. However, he may also try to convince the competent authority in an other way that his products are in accordance with the essential requirements. The standards are only used as a reference. Two basic types of standards will be used: horizontal standards and vertical standards. Horizontal standards apply to a variety of devices and concern, for instance, biocom- patibility or labelling. Vertical standards deal with a specific product category.

The medical devices subject to this directive are classified. In an annex of the directive, class selection criteria are described. The classification is based upon the risks involved in using the device. Under "use" is understood use according to the manufacturer's directions and intentions. A three-class system is meant to impose requirements, relative to the risk. To the low risk class (class I) belong devices like dressings and wheel chairs which, if used in accordance with the intentions, "do not present a foreseeable risk of irreversible illness or injury". In class $\Pi \mathrm{a}$ and $\Pi b$ ("intermediate risk"), devices are classified which may cause such a risk. However, these devices do not cause risk of death. More critical devices belong to class Ib. Devices classified in class III, "high risk" devices, present risk of death or serious damage. Artificial heart valves, for example, belong to this class.

\section{The conformity assessment procedure}

In the annexes of the directive the conformity assessment procedures are described. These procedures indicate how conformity of a device with the requirements may be shown. The manufacturer may choose between several conformity assessment procedures (except for class I). A distinction is made between the design and the manufacturing of a device. Relative to class I medical devices, the manufacturer carries the responsibility for compliance with the essential requirements. No third party certification is required. The manufacturer must keep documentation of the design and manufacturing process available and present.

Relative to class IIa medical devices, the manufacturer himself may establish design conformity. With regard to the manufacturing process, third party intervention will be necessary. A certified quality assurance system will be needed to prove compliance with the requirements (this may be based on the European Standard 29002). Relative to the more critical class IIb and class III devices, third party intervention by a "notified body" is required.

In the directives, two official bodies are charged with supervising duties: the "notified body" and the "competent authority". The first one is foremost charged with the issue of the declaration of conformity, the last one has a more general supervising duty regarding the execution of the draft in the member states.

\section{Consequences of the "European Community directive on medical devices" for joint prostheses}

On the basis of the following rule of the draft it may be 
established whether a joint prosthesis will be classified in class IIb or III:

"Rule 7: All implantable devices and long-term surgically invasive devices are in Class IIb unless they are intended:

- to be placed in the teeth, in which case they are in Class IIa;

- to be used in direct contact with the heart, the central circulatory system or the central nervous system, in which case they are in class III;

- to undergo chemical change in the body, to be biologically active, to be fully or largely absorbed, to supply energy in the form of ionizing radiation or to administer medicines, in which case they are in class 11 , except if the devices are placed in the teeth."

According to rule 7 implants belong in class III if they are used in direct contact with a vital organ or tissue and in class IIb if this is not the case. As a consequence, joint prostheses will be classified in class IJb in principle. However, if they are covered with a bio-active coating (hence, cause "biological activity"), they will, most probably, belong in class III.

The "essential requirements" joint prostheses have to meet are described in the draft. A joint prosthesis has to be adequately safe as far as physical, mechanical, biological, and chemical qualities are concern regarding use in conformity with the manufacturer's intended purpose. This manufacturer's "intention" must become evident from the labelling or the instructions, unless this use is self-evident. Measures must be taken so that the manufacturer of a prosthesis can be traced. If a prosthesis is brought on the market and causes risks topatients or users, the manufacturer must have a suitable system to be able to take corrective action ("post marketing surveillance").

Remarkable is that, in contrast with the American and the French systems, the admission to the market is evaluated based on the question whether the prosthesis meets the "Essential Requirements". The performance of the prosthesis, as it should be documented with the results of "clinical trials", is not mandatory, unless the manufacturer chooses certification of his quality assurance system by a notified body. With regard to prostheses that might be classified in class III (bio-active coated) the quality assurance system of the manufacturer will have to be certified by a notified body. In this case "design approval" will be necessary and therefore the manufacturer will have to submit clinical data. He may do this by a collation of relevant scientific literature or by submitting the results of all clinical investigations made with the device in accordance with the requirements of the directive.

Regarding joint prostheses, the requirements of this draft-directive have a general character and the admission to the market will not occur on the basis of the results obtained in long-term clinical trials, as happens in the United States and France.

\section{Summary and analysis of the law systems}

In this chapter short analyses will be given of the law systems that were described. The life cycle model (basic and clinical research, design, manufacturing, marketing, application, and follow-up) will be used to describe to which stages the regulations apply.

\section{The law systems and the implant life cycle}

\section{Basic and clinical research}

In the United States and in France, clinical data must be available in order to obtain market approval. As a consequence, clinical trials will have to be carried out. In the United States, the FDA requires "valid scientific evidence" with regard to the safety and effectiveness of new joint prostheses (21 Code of Federal Regulations par. 860.7). With regard to new Class III-prostheses, the results will have to be approved before market approval may be obtained. Specific legal requirements exist with regard to the way in which this research is carried out. Protocols have to be followed in which patient consent and protection are also important aspects.

In France, the market approval system is primarily based on the results of clinical trials. Each prosthesis, whether it is original, identical, modified or innovative, will be evaluated against its clinical performance. The requirements are even stricter than in the United States, where the "Substantial Equivalence" route allows new (although equivalent to an "old") prostheses on the market without submission of clinical data.

In the future European Community directives, submission of clinical data will only be required with regard to class III devices. Only prostheses with a bioactive component, for instance a coating, will fall into this class. All other prostheses will be in class IIb. Hence, future new joint prostheses (unless they are bioactive) will get the CE-mark ("Conformité Européen") without submission and approval of clinical data by an official authority and are, as a consequence, allowed on the market all over Europe.

Nor in the Netherlands, nor in the United Kingdom or Germany there is a specific requirement to carry out tests or clinical trials in order to prove the safety and effectiveness of new medical devices. Hence, it is possible to introduce a new joint prosthesis on the market without submission of any clinical data to a government body.

\section{Design}

In the United States, in the recent changes to the Medical Device Amendments, a specific requirement has been made with regard to design-validation. This 
requirement will be implemented as a good manufacturing practice-concept. It includes the requirement that device manufacturers, as a pre-production manufacturing control, implement a process that will demonstrate that the device will perform in accordance with the intended purpose. In the French system, testing of the design forms part of the homologation procedure. Design validation is also a recognized means of production quality control in the future European Community directives and will be mandatory as an "Essential Requirement" with regard to class III devices. Nor in the Netherlands, nor in the United Kingdom or Germany at present, there is a legal obligation regarding the design stage.

\section{Testing}

In the United States and in France, it is required that the prosthesis is tested with regard to its mechanical, chemical-physical and histomorphological characteristics. This has to be done before it is allowed on the market. In the Netherlands there is, at the moment, no testing requirement. In the future European Community system, the manufacturer will have to test his prosthesis in order to obtain proof that the prosthesis is in accordance with the essential requirements.

\section{Manufacturing}

Both the United States and France have enacted statutory requirements regarding the manufacturing process. In the United States, the basic principle is that the manufacturer has to work in accordance with "Good Manufacturing Practices." These "GMP's" are drafted by the FDA and include regulatory inspections of the plant. In France the manufacturer may have his production process certified. However, this is not obligatory. In the future European Community directives the manufacturing process is emphasized. In order to manufacture safe medical devices, the principle is that quality assurance systems are applied to the manufacturing process. The requirements for these systems are found in quality-system standards (based on the original ISO 9000 series: EN 29000 series). The main obligation for the manufacturer is that he manufactures a safe medical device that does not compromise the safety and health of patients when properly installed, maintained and used in accordance with its intended use. In the Netherlands there are no specific legal requirements with regard to the manufacturing process. Manufacturers may follow Good Manufacturing Practices, drafted by trade organizations, on a voluntary basis. This is also the case in the United Kingdom.

\section{Marketing}

The United States and France are the only countries in the world with a detailed market approval system comprising requirements especially drafted for joint prostheses. Hence, the transition from the stages manufacturing to marketing is legally regulated. As a consequence, approval has to be obtained prior to marketing of the product. In the European Community system the general requirements, applying to all medical devices, require the manufacturer to obtain the CE-mark prior to marketing of the prosthesis. At present, there is no such requirement in the Netherlands, nor in the United Kingdom or Germany. The marketing stage itself, as it is described in this survey, is nowhere regulated by law, with the exception of labelling and directions for use.

In the United States and also in the European Community directives, labelling and directions for use must accompany the device. In France, the prosthesis must be labelled if it is still in the process of being homologated. However, these are obligations for the manufacturers and there is no specific requirement for users, that is the orthopedic surgeon, to follow these instructions.

\section{Clinical application and follow-up}

Not one law system entails specific requirements with regard to the clinical policy of total joint prostheses. Training and education may be regulated in generally applicable rules and regulations, but not in medical device legislation as examined in this survey. In the United States the manufacturer is required to have a device tracking system and must report problems regarding medical devices. Problem reporting is also obligatory with regard to users of medical devices. In France and in the United Kingdom, problem reporting is voluntary. In the European Community directives, the traceability of a device must be organized by the manufacturer as a component of his quality assurance system (En 29000 series' standards).

As described above, in France and sometimes in the United States, clinical evidence is required in order to obtain market approval. As a consequence, the followup stage will be regulated, but only with regard to prostheses which are legally required to participate in a clinical trial.

\section{Discussion and conclusion}

The market approval procedure, as it is mandatory in the United States, has advantages and disadvantages. If the newly developed prosthesis is found not to be "substantial equivalent" to a prosthesis already on the market, the arduous pre market approval (PMA) procedure will have to be followed. This inciudes obtaining approval to conduct the required clinical trials (Investigational Device Exemption; IDE) and actually 
performing these trials. This may take 6 to 7 years. In addition, these PMA procedures entail high costs for the manufacturer.

The requirement of clinical trials means that the results of these trials must be considered and judged. The FDA officials do not possess the expertise to formulate a valid scientific judgement themselves. For that reason an Advisory Panel comprising of medical experts in this field ("Orthopaedic and Rehabilitation Panel") has been set up. This Panel has to give an independent verdict on each PMA application. The FDA may adopt this advice or reject it. This system leads to an informed judgment on the one hand, on the other hand it also causes much bureaucracy. The procedures take much time and money. The advantage of the American system is that it functions as a "sieve" and chances are high that in this way really inferior prostheses are rejected. Hence, the "benefits" of this system are obvious, but it is also evident that the "costs" are high. On the one hand these include the tax-payers costs for the FDA organization and bureaucracy, and the costs to the manufacturers for the trials and testing procedures. On the other hand these "costs" also include the risk that a really beneficial innovation is retarded from reaching the public. A good example of this is the timelag in the market approval of acrylic cement, now widely acknowledged as the innovation which brought success to joint replacement. The tedious American system may even discourage small companies and "inventive users" to follow-up on new ideas and discoveries.

It is also obvious that even the tedious FDA system is not capable of banning inferior products from the market entirely. Many of the products which failed, discussed in section 2.1 , were freely available on the US market, some after going through the arduous pre market approval (PMA) procedure. A notorious example is the Mittelmeier total-hip prosthesis, which was approved by the FDA, just shortly before excessive clinical failures were reported at European meetings. Another example is the PCA total-knee prosthesis, shown to produce early excessive wear and polyethylene failure (Engh 1988, Tulp 1992, Wright et al 1992), but allowed on the market by PMA approval P840049. In both cases, the problems emerged much later than the 2 years trial period required by the FDA. Another aspect that these two examples have in common is that their main innovative features were not the prime causes of the failures. The Mittelmeier was innovative particularly because of its ceramic head and cup, but failed in the stem fixation. The principal innovative feature of the PCA was its porous coating, but failures were due mainly to polyethylene wear.

The French approval system has not functioned for a long time yet, and hence caution is justified in criticiz- ing its effectiveness. The classification of the prostheses appears to be better related to their specific quality problems. In France we find a committee of experts ("Sous-Commission Suppléance Fonctionnelle Orthopédique") to assess the results of clinical trials, and a special task force to draft protocols for clinical trials and technical test procedures. In the United States this is organized in a different way: the FDA instructs the manufacturer in what way the clinical trials must be organized and executed. One tries to standardize this by way of so-called "guidance documents" but still each IDE request is evaluated and approved individually. This appears to be a time consuming matter. In the absence of an agency like the FDA, the French committee of experts has much more influence than its American counterpart ("Advisory Panel"). In France the subcommittee is independent, in the United States it is regarded by the FDA as an annex to its own administration.

Although France lacks a bureaucratic institution like the FDA, the procedures of its approval system do require much organization and efforts of the committees involved. Efforts which, eventually, will have to be paid for by the public, through taxes or insurance premiums. It is still too early to determine whether and to what extent this system discourages new developments or retards the introduction process of innovations, or to which extent unsafe products may go undetected.

The situation in the Netherlands, as well as in the United Kingdom and in Germany, is that there is no statutory "regulatory system" for joint prostheses at all. In the Netherlands, the manufacturer must only ensure that his products meet the requirements regarding sterility. In the United Kingdom, the (voluntary) system is focused on control of the manufacturing process of suppliers to NHS hospitals ( $90 \%$ of the manufacturers). The costs of this system are, obviously, negligible in terms of money. To which extent it has created avoidable hardship on patients is unknown.

With regard to the future European Community directives, market introduction is not preceded by a "blockade" in the manner of an approval procedure during which clinical results are assessed by a specially assigned committee, as is done in the United States or in France. Priority is given to quality assurance of the manufacturing process, which is validated by compliance to harmonized standards. In many ways, it is unclear as yet how the European Community system will work in practice. Much will depend on the efficiency of the standardization procedures and on the effectiveness of the standards to be developed. If we weigh the potential negative effects of the systems on innovation and development against the risks of unsafe devices to be marketed, the balance probably tends more to 
the latter side in the European Community system, as compared to the USA and French systems.

In conclusion, an accurate and useful cost-to-benefit analysis of the different systems is difficult, partly because they have not been in existence very long and partly because no systematic research of these costs and benefits have been performed in any of the systems. Although no evidence to the contrary can be found, there is certainly no prove to the extent that systems with strict, government enforced legislation provide less risks for patients than expert-based systems with less government control.

Returning to the implant life-cycle model (Figure 1), it is evident that most legal requirements in the different systems relate to product quality characteristics only. Service quality characteristics, as they are the most relevant for the patients, as we have seen in the previous chapter, are hardly considered. The emphasis in the law systems is on protection against unsafe devices, for which design, testing and manufacturing may have been regulated. Quality assurance of joint replacement as a whole is not considered. 


\section{The responsibility of the orthopedic community and quality assurance}

\begin{abstract}
"Man's ingenuity has developed first and his soul afterwards. Thus the progress of science is far ahead of man's ethical behavior." (Charley Chaplin)
\end{abstract}

\section{Alternatives to government regulation}

As we have seen in the previous chapters, regulation is mostly used to protect against unsafe prostheses. We have also seen, in section 2.1 , that problems are not only caused by unsafe devices, but also by incorrect applications. The stages "application" and "follow-up" are not covered by specific law requirements. The question arises whether government regulation is the correct instrument to influence the complete service quality aspects of total joint replacement. If government regulation can not be used to assure and improve service quality dimensions, what are the alternatives? In this final chapter we compare four "regulatory models," three of which are alternatives to government regulation:

- Self discipline;

- Self control;

- Self regulation;

- Government regulation.

These models vary depending on the person, group of persons or authority which sets the standards and the extent to which these standards are obligatory and enforced (Faro 1990):

- Formulation of standards: government, or party involved (orthopedic community), or government together with party involved.

- Enforcement of standards: government, or parties involved (orthopedic community), or government together with party involved.

\section{Regulatory models}

\section{Self discipline}

In the "self discipline" model it is the individual, the health care professional himself who sets his own standards and who decides whether he has to abide by them. It is to be expected that his behavior will be more or less similar to that of his peers; he will act according to the "state of the art". The "state of the art" may be modified if the results of scientific research require so.
The individual surgeon will tend to adjust his behavior and act in accordance with the new standard. When for instance a high rate of early loosening with the Christiansen prosthesis was reported (Josefsson et al 1981), surgeons had to decide whether there was still an indication for use of this prosthesis. As can be seen in Figure 2 (Ahnfelt et al 1990), there was indeed a steady. decline in the application of this prosthesis during 1981 and 1982, but even in 1983 and later a few were implanted. If an individual surgeon deviates from the common standard, his behavior may be judged by an external institution, for instance a disciplinary or, in an extreme case, a criminal court.

\section{Self control}

In the model of "self control" the standards are formulated by a group of parties involved, hence a group of experts originating from the orthopedic community. These standards may relate, for instance, to surgical techniques or diagnosis,but also to the admission of new devices. However, they are not embodied in "enforceable" rules. Orthopedic surgeons will, on a voluntary basis, submit to these recommendations. A good example of "self control" is consensus develop-

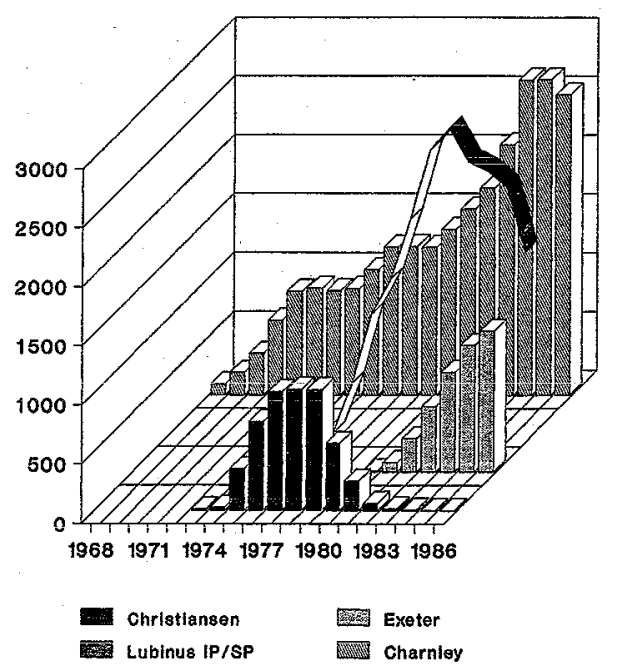

Figure 2. The use of the Christiansen prosthesis in Sweden according to Ahnfelt et al (1990). 
Table 1. A suitable regulatory scenario

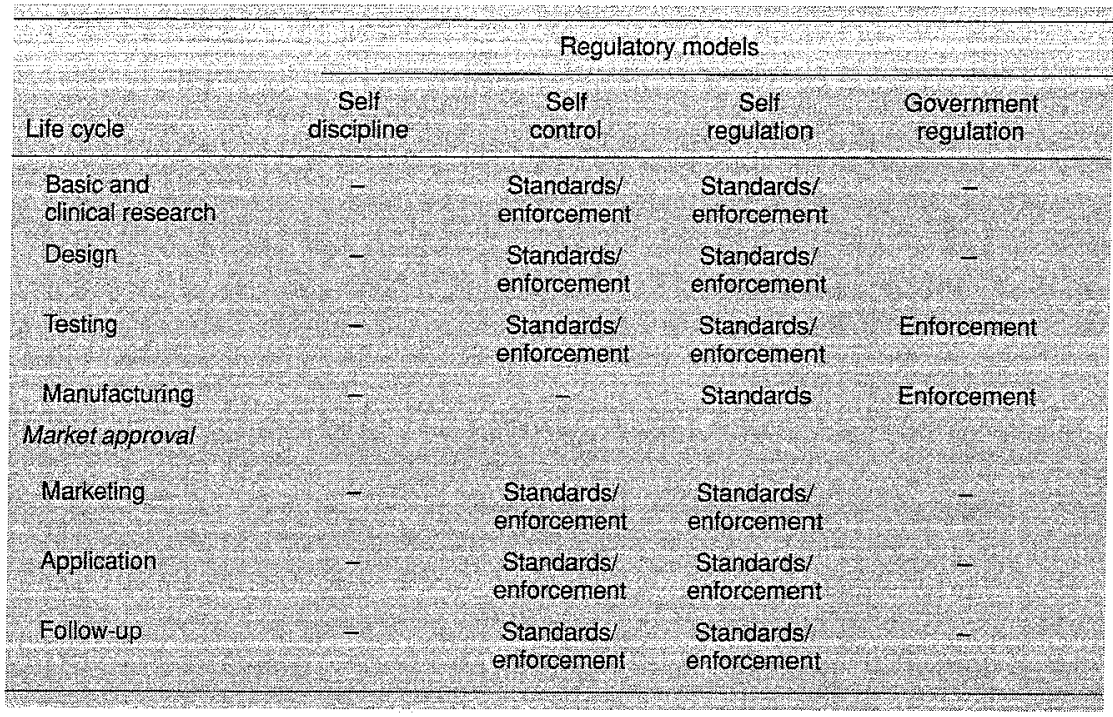

ment conferences. These conferences result in recommendations for the orthopedic community. These recommendations are not considered to be strict "rules"; there is no established method of enforcing all practitioners to follow the recommendations (Kosecoff et al 1987, Calltorp 1988).

\section{Self regulation}

"Self control" is not synonymous with "self regulation:" in the "self regulation" model, "enforceable rules" are applied. In principle, all persons who belong to the group (in this case the orthopedic community) are obliged to submit themselves to the rules. "Self regulation" resembles "government regulation". The difference is the authority which drafts and embodies the standards into rules and regulations. In the "self regulation" model, a representative group of persons composed of members of the orthopedic community will draft and embody the standards.

Policies based on self regulation will only be effective if the parties involved are willing to follow the standards agreed upon. If a considerable amount of orthopedic surgeons consider themselves not to be "involved", self regulatory policies will be useless. Another problem concerns the enforcement of the standards. Which sanctions can be taken against breakers of the rules? Fines or disciplinary sanctions are possible, in the extreme case the person involved may be suspended from membership of a society. However, prison sentences or other more serious sanctions will not be possible.

\section{Government regulation}

In the "government regulation" model, government authorities draft the standards and the rules. They also take care of the enforcement. In a "government regulation" model the rules will be compulsory for all, even if one does not belong to a particular group. Enforcement may go as far as fines or even prison sentences, but only if they are embodied in the law.

\section{Some süggestions regarding a suitabie regulatory scenario with regard to total joint replacement (Table 1)}

Above we described alternatives to the government regulation model. These regulatory models may be considered relative to the life cycle model. The objective is to conceptualize a system of total quality assurance with regard to the implant life cycle. In each stage of the life cycle we will suggest a most suitable regulatory model.

\section{Basic and clinical research}

Basis research provides the "body of knowledge" from which innovations may be derived, standards may be developed and on which tests may be based. In the field of joint replacement this body of knowledge is a multidisciplinary one, involving cell biology, biomechanics, 
biomaterials, physiology, anatomy and pathology. According to Huiskes (1990) basic research in this field may be categorized as

- Activities aimed at providing basic information regarding the function and malfunction of joints, and the biological and biomechanical properties of their associated tissues.

- Activities aimed at uncovering and evaluating biological and biomechanical failure mechanisms of joint replacements.

- Development of clinical and experimental research tools.

The evaluation of the clinical performance of a joint replacement will take place through clinical research. In general, "randomized clinical trails" are defined as the "gold standard" for performing clinical research (Gartland 1988, Rudicel and Esdaile 1985, Saha and Saha 1987). Yet in orthopedics, little use is made of this method. Gross did a literature research over the years '60-'86 and discovered only 4 studies using prospective research in hip joint replacement (Gross 1988). Already before that time, in 1985 a search was done by a number of authors, however not exclusively directed at research in hip prostheses, but at orthopedic surgery in general. They got as far as a total of 4 publicized "randomized clinical trials" (Rudicel and Esdaile 1985).

\section{Design and testing}

According to Webster's New Riverside University Dictionary, to design means to "conceive in the mind," to "invent" and "to plan by making a preliminary sketch." It also contains an artistic element: "to create or execute in an artistic or highly skilled manner." All these elements are needed in the complex process of trying to find a solution to the replacement of a diseased joint.

"The structure and function of human joints is so complex and currently so little understood that it is probably unwise to attempt to copy nature too closely when replacing a natural joint by an artificial one" (Jobbins 1981). This statement nicely summarizes the present limitations in artificial-joint designs. The goal of mimicking the real joint is simply too ambitious at the present time. A realistic objective is to design a prosthesis which causes no pain and allows for a reasonable normal function during 20 to 30 years. In the past development took place through "trial and error", using the operating room as the laboratory and the patient as an experimental model (Huiskes 1990). However, this process of clinical evaluation, modification, and reevaluation through a clinical trial is not considered a "design procedure". A design-procedure is understood as "a particular process with specific objectives, methodologies and evaluation procedures that are incorporated into a process in specific and related ways" (Burstein 1988). In this stage conformance to design specifications and preestablished standards is important. These specifications and standards will have to be determined by both bio-engineering specialists and orthopedic surgeons and may forinstance include (Burstein 1988):
Specification

Relief of pain

Without physical

impairment

Longevity of the device, that is no mechanical or biological failure

Compatibility of the device with the human body
Standard

- Able to live a normal life

- Able to live a normal life

-25 years

- Equilibrium
Both specifications and standards vary according to the views and opinion of the designer. However, the objective in this stage is to aim at the optimal design.

In the testing stage methods and standards are developed and applied for preclinical testing of the prosthesis in the laboratory before it is first tried in patients.

\section{Choice of regulatory model with regard to the stages basic and clinical research, design and testing (Table 1)}

The stages basic and clinical research, design, and testing are all three investigational phases in the life cycle and belong to the innovation process. There will not always be a sharp distinction between the separate stages and information will flow from one stage to another and backwards. Although it would be unwise to regulate basic research in any way, several other aspects need emphasis in this stages, like the advancement of a certain consensus in the "designs" of clinical studies and the objective interpretation of research results. In this stage it might also be valuable to register exactly where and which clinical trials are being carried out. In order to do so, the concerted group will have to formulate criteria; they possess the expertise that is needed to accomplish this task. Leaving it up to the individual to draft his own standards, hence the self discipline model, is less desirable in this stage. Depending on whether members of the group are willing, on a voluntary basis, to submit to the recommendations of the group concerning these issues, the model of self control or self regulation may be chosen. If necessary, government control might be helpful in enforcing the standards. 


\section{Market approval and choice of regulatory model} (Table 1)

After these pre-market stages, the decision will be made whether the implant is ready to leave the experimental stage and is acceptable for adoption in daily practice. The decision about market approval has to be taken. The decision must be based on an assessment of prosthetic quality. This assessment must be done by experts, most probably gathered in an advisory panel (like in the United States or France). This panel has to devote its attention to the results of pre-clinical and clinical trials with joint prostheses. If there is no existing classification, a classification should be formulated, or the French classification (i.e. original prostheses, identical prostheses, modified prostheses, innovative prostheses, and special prostheses) could be taken. All prostheses available on the market should be classified and subsequently a market approval system should be developed. The French system may serve as an example in this respect. The drafting of standards regarding this decision should be done by experts, that is "parties involved", from the orthopedic community. However, enforcement of a market approval system might be more problematic if exercised on a voluntary basis. The manufacturer might find himself in a conflict of interest between the marketing of a new prosthesis and patient protection. As a consequence, external and independent control may be needed to enforce the system.

\section{Manufacturing and choice of regulatory model (Table 1)}

Prior to manufacturing, a decision has to be made on materials specifications. The manufacturing process may be divided into four activities: basic forming processes, machining and finishing processes, material treatments, and quality control (Atkinson and Jobbins 1981). In the basic forming process the prosthesis is shaped; this may be done for instance by forging, moulding or welding. The basically formed implant is subsequently given its final shape, size or surface finish in the machining and finishing process. Next, the prosthesis' materials will be treated. Material treatments are applied to improve the structure of the material, to improve the structure of the surface chemically or to improve the surface in terms of finish. As a last procedure in the manufacturing stage quality control, inspection of the prosthesis, will take place.

The same considerations as mentioned above regarding the regulatory model apply to the "manufacturing" stage: the drafting of the standards should be done by experts, external control may be needed to enforce these standards. The future European Community system is a good example how this may be organized by industry and government together. Hence, a combined system of government and self regulation is preferable.

\section{Marketing stage and choice of regulatory model (Table 1)}

In the marketing stage, the prosthesis is introduced on the market. Hospital administrators and/or orthopedic surgeons will make the purchasing decision. This decision will depend upon how prosthetic quality is perceived: how do the results of the prosthesis compare to other prostheses, what kind of surgical techniques and instruments have to be used, how does it look, what do colleagues say about it, which company is manufacturing it, etc. The decision will also be influenced by the quality characteristics that are prioritized. These characteristics might differ according to the circumstances, the prosthesis that is needed or the budget that is available. The manner in which the prosthesis is presented in either literature, on conferences or by sales people is important in this respect. Like in the drugs area, there might be reason to put advertising and promotional activities under some kind of regulatory control. In first instance self control or self regulation will be the applicable regulatory model. If these models do not succeed on a voluntary basis, government assistance might be needed.

\section{Application stage and choice of regulatory model (Table 1)}

The objective of using a prosthesis is to provide the patient with a treatment which results in neither pain nor functional impairment for as long as possible. Loosening of the prosthesis which causes pain means failure of the replacement and may lead to revision of the prosthesis. Adequate fixation of the prosthesis into the bone is an important factor with regard to the survival rate. Fixation of the prosthesis, with or without cement, depends on a good bond between prosthesis and bone. The most important factor affecting the strength of this bond is, according to Charnley, the surgeon (Older 1986). Long-term success of an implantation depends to a high degree upon the expertise of the surgeon himself. Cementing techniques are, according to Charnley, "the sine qua non of a successful total hip arthroplasty and any surgeon who thought of cement as a glue was doomed to failure." Skills are of the utmost importance and Charnley had a hard time imagining that there were surgeons who "would spend a great deal of time perfecting a game of golf but make no such effort to improve surgical technique" (Older 1986).

In the application stage, important aspects are the 
surgical procedure, training and education. Diagnosis and surgical techniques are matters which are strongly influenced by the professional autonomy of the surgeon himself. Education and training may be organized, as it often is already, through "self regulation". In this stage, government regulation is hardly imaginable because of the lack of expertise necessary to set the right standards and also because of the fact that "the state of the art" will change continuously. Amending the law for each change will be virtually impossible. Hence, the drafting of standards and guidelines regarding orthopedic care should be done by the orthopedic community. Enforcement of these standards is in the first place the responsibility of the orthopedic community itself. This can be done by a group of surgeons representing the orthopedic community. To summarize, this results again in a choice between self control and self regulation as optimal regulatory models.

\section{Follow-up and choice of regulatory model (Table 1)}

In the "follow-up" stage two aspects are relevant:

- The follow-up of individual joint-replacement patients by individual surgeons.

- Registration of implantations and reoperations at large in order to determine survival rates of prosthetic designs.

In this stage, clinical follow-up of patients with an implanted prosthesis must be performed by the individual surgeon. Outcome assessment may be done by using a standard evaluation scoring system (Müller et al 1990, Liang et al 1991). In orthopedics, long-term follow-up studies are essential (Wroblewski 1986). Registration of complications and revision operations are important in order to assess the long- term risk of failure of implants (Ahnfelt et al 1988, Ahnfelt et al 1990).

In this stage, the same considerations apply as in the previous stage: government regulation is hardly imaginable to regulate the way in which a surgeon looks after his patients after having operated on them. The choice will be between self control and self regulation.

\section{The suitable regulatory scenario and the quality assurance process}

In the first chapter the risks of unrestricted innovation have been shown: new procedures will be introduced too soon without awaiting long-term results. Examples were the Judet prosthesis, surface replacement, the
Mittelmeier prosthesis and, in the Nordic countries, the Christiansen prosthesis. If no requirements are made, it is left to the inventor-surgeon or manufacturer to decide the moment of market introduction: hence, the model of self discipline.

In this survey, the life cycle model (Figure 1) has been used to describe the concept of a prosthesis passing different stages through time. The removal of the prosthesis from the body (or the death of the patient) is the end stage. The scientific information regarding the prosthesis is subsequently used in the basic and clinical research stage and thus a new cycle begins. In this respect the life cycle is an iterative process. With regard to the quality assurance process, the life cycle in total needs consideration. In short, besides assurance of the quality of the product, assurance of the quality of the joint replacement procedure has to be organized. As a consequence, the stages "application" and "follow-up" must be focused on. As we argued based on our analysis, this does not occur at the moment and the question is, whose responsibility is it? Regarding the "operating surgeon's expertise", the influence of the lawgiver shifts more to the background, considering the professional autonomy of health care professionals and the rapid changes in the "state of the art". Government regulation may comprise prerequisites regarding the status of the expertise, but can not prescribe, for instance, operating techniques or implant choice. Relative to the patient, influencing his "quality" dimensions (age, physical condition, level of activities) by law is (of course) not a realistic option. They can only be addressed through the orthopedic surgeon.

In order to assure quality in an acceptable manner, there should be a quality assurance system which is composed of at least four components:

- Standards;

- Mechanisms to draft standards;

- Mechanisms to measure quality;

- Mechanisms of enforcement.

Regulatory models may be used to advance the creation of such a system. As demonstrated in the description of the present regulatory systems, government regulation is almost always concentrated on product quality characteristics. Service quality characteristics as they are important in the application stage are not specifically regulated by law.

With regard to the drafting of standards, this should be done by experts, either in a government organized committee (France) or in a self-regulatory committee, organized by the orthopedic community.

Measurement of quality may be done through multicenter clinical registration of joint replacements and reoperations. Most important aims of these registrations are (Ahnfelt et al 1990): 
- To evaluate the interrelationship of individual, surgical, and prosthetic parameters with total joint replacement failure;

- To calculate survival rates for different age groups and different implants for prediction of the long-term endurance;

- To disseminate information to the orthopedic profession and to reduce the number of procedures that do not serve the patients well.

This shows that registration is of the utmost importance if we want to measure not only product quality but also surgeon related quality characteristics. The system as it functions in Sweden is a good example of a quality assurance mechanism set up through a self control model. All orthopedic surgeons participate on a voluntary basis. If they appear to be not so cooperative, government might assist in the enforcement.

In the suggested regulatory scenario (Table 1) we notice that the focus is on self control and self regulation: the orthopedic community should take its responsibility and start organizing quality assurance systems as described above. With regard to the product quality characteristics, manufacturers have their own responsibility, in particular in the manufacturing process. With regard to basic and clinical research, design, testing and follow-up of the prosthesis, industry has a shared responsibility with the orthopedic community. Governments should have a supportive role in the quality assurance process and, if necessary, assist in the enforcement.

In conclusion, it is clear that in an optimal regulatory scenario, quality assurance in all stages is the responsibility of the concerted parties; they are the experts and they in the first place, should draft standards and measure quality. The most suitable regulatory model will be in the first place self control and if more stricter regulation is necessary, self regulation. Government control will be needed as an external check in the stages testing, manufacturing and in enforcing the decision on market approval. In the application and follow-up stage, the enforcement of the standards is in the first place the responsibility of the orthopedic community.

\section{Acknowledgement}

The authors wish to thank Frits Faro for all his work in translating and commenting on the original manuscript, Ben Veraart for his valuable and critical remarks and Ortomed BV for financial support.

\section{Correspondence:}

Laurie M C Faro, JD, PhD

Ortomed BV

PO Box 1081

3330 CB Zwijndrecht

the Netherlands

Tel +3178102010

Fax +3178104265 


\section{References}

Abbott L. Quality and competition. Columbia University Press, New York 1955.

Ahnfelt L, Herberts P, Andersson G B J. Registration of complications in total hip arthroplasties. Acta Orthop Scand 1988; 59: 353-56.

Ahnfelt L, Herberts P, Malchau H, Andersson G B J. Prognosis of total hip replacement. Acta Orthop Scand 1990; 61 (Suppl 238): 1-26.

Amstutz H C, Thomas B J, Jinnah R, Kim W, Grogan T, Yale C. Treatment of primary osteoarthritis of the hip. A comparison of total joint and surface replacement arthroplasty. J Bone Joint Surg (Am) 1984; 66: 228-41.

Arrêté du 9 décembre 1982. Journal Officiel du 5 janvier 1983. Arrêté du 23 mai 1984. Journal Officiel du 29 juin 1984.

Arrêté du 24 février 1987: Prothèses internes articulaires. Journal du 11 mars 1987.

Atkinson J R, Jobbins B. Properties of engineering materials for use in the body. In: An introduction to the biomechanics of joints and joint replacement (Eds. Dowson D, Wright V). Mechanical Engineering Publications Ltd. London 1981: 161-71.

Bauer $\mathrm{G} \mathrm{C} \mathrm{H}$. What price progress? Failed innovations of the knee prosthesis. Editorial. Acta orthop Scand 1992; 63: 245-246.

Burstein A H. The uncemented arthroplasty: new rules for design for the femoral component. In: Non-cemented total hip arthroplasty (Ed. Fitzgerald R H Jr). Raven Press Ltd. 1988: 335-38.

Calltorp J. Consensus development conferences in Sweden, effects on health policy and administration. Int $J$ Technology Assessment in Health Care 1988; 4: 75-88.

Chamley J. Letters to the editor: Tissue reactions to polytetrafluorethylene. The Lancet 1963: 1379.

Christel $P$. The regulation of orthopaedic devices in France. $J$ Biomed Mater Res: Applied Biomaterials 1989; 23 (A1): 27.

Commission Nationale d'Homologation. Approval procedure for medical devices in France: benefits from clinical testing. Officiel document, French Department of Health 1987.

Commission of the European Community. Draft for a Council Directive on medical devices. COM 287 def-SYN 353, August 23 1992: European Community Publication Journal C 237 of September 121992.

Council of the European Community. Resolution of May 7 1985. European Community Publication Journal of June 4 1986: Nr. C 136.

Cook S D, Barrack R L, Thomas K A, Haddad R J. Quantative analysis of tissue growth into human porous total hip components. J Arthroplasty 1988; 3: 249.

Cox W E. Product life cycles as marketing models. The Journal of Business 1967; 40(4): 375-84.

Crosby Ph. Quality is free. New American Library, New York 1979.

Department of Health and Social Security. Quality assurance, the manufacturer registration scheme. Her Majesty's Stationary Office 1988; nr. 11.
Dhalla N K, Yuspeh S. Forget the product life cycle concept! Haryard Business Review 1976; Jan/Feb: 102-12.

Dobelle W N. Minimizing the adverse effects of the Medical Device Amendments of 1976 on innovation in artificial organs research. Artificial Organs 1977; 1: 65-75.

Donawa $\mathrm{M} E$. The control of medical devices in the United Kingdom. Medical Device Technology 1992; August/ September: 8-11.

Douley R L, Engel C, Müller M E. Automated scanning and digitizing of roentgenographs for documentation and research. Clin Orthop 1992; 274: 113-119.

Duncan $M$. The control of sterile medical devices and surgical products in the United Kingdom. In: Proceedings of the EUCOMED conference "Regulation of medical devices and surgical products in Europe," Brussels, Belgium 1987: 5-8.

Ebramzadeh E, Sarmiento A, Llinas A, Zahiri C. Effect of stem design and material on the log-term radiographic behavior of THR. Trans. 38th ORS, Washington, DC, 1992 300.

Editorial. Quality control of implants. Acta Orthop Scand 1987; 58: 477-78.

Edwards C D. The meaning of quality. Quality Progress 1968; $37-41$.

Engh C A, McGovern M F, Bobyn J D, Harris W H. A quantitative evaluation of periprosthetic bone-remodeling after cementless total hip arthroplasty. J Bone Joint Surg 1992; 74: 1009-1020.

Engh G A. Failure of the polyethylene bearing surface of a total knee replacement within four years. J Bone Joint Surg (Am) 1988; 70 (7): 1093-96.

Faro L M C. De Wet op de medische hulpmiddelen, een evaluatie-onderzoek. Erasmus Universiteit Rotterdam, the Netherlands, Beleid en Management Gezondheidszorg 1986.

Faro L M C. De kwaliteit van implantaten in juridisch perspectief, reguleringsscenario's voor de totale heupprothese. Thesis, Erasmus Universiteit Rotterdam, the Netheriands 1990.

Food and Drug Administration. Guidance for the preparation of premarket notifications for ceramic ball hip systems. Rockville 1989, April 27.

Food and Drug Administration. Zimmer USA, premarket approval of biological ingrowth anatomic stem fiber metal total hip system. Federal Register 1989; 54: No. 97, 22019.

Feigenbaum A V. Total quality control. Mc Graw Hill, New York 1961.

Feith $R$, Megens $H$. The ceramic total hip prothesis (Type Mittelmeier). Acta Orthop Scand 1986; 57; 390.

Freeman M A R. Total surface replacement of hip arthroplasty. Clin Orthop 1978; 134: 2-4.

Freeman M A R, Bradley G W. ICLH surface replacement of the hip. An analysis of the first 10 years. J Bone Joint Surg (Am) 1983; 65: 405-11.

Gartland $J$ J. Orthopaedic clinical research, deficiencies in experimental design and determination of outcome. $J$ Bone Joint Surg (Am) 1988; 70: 1357-64. 
Garvin D A. Managing quality, the strategic and competitive edge. Free Press, New York 1988.

Gezondheidsraad. Rapport betreffende toezicht op de hoedanigheid van medische materialen, waaronder hier worden verstaan metalen voorwerpen, bestemd voor plaatsing in het lichaam. 's Gravenhage 1963.

Gilmore H L. Product conformance cost. Quality Progress 1974: June; 16-21.

Goodfellow J. Knee prostheses - one step forward, two steps back. J Bone Joint Surg (Br) 1992; 74: 1-2.

Griffin J P. Medicines control within the United Kingdom. In: Medicines: regulation, research and risk (Ed. Griffin J P). Queen's University, Belfast 1989: 1-27.

Gross M. A critique of the methodologies used in clinical studies of hip-joint arthroplasty published in the Englishlanguage literature. J Bone Joint Surg (Am) 1988; 70: 136476.

Guaspari J. "I know it when I see it", a modern fable about quality. Amacom, New York 1985.

Harris W H. Advances in total hip arthroplasty: The metalbacked acetabular component. Clin Orthop 1984; 183: 4.

Hauptman O, Roberts E B. FDA regulation of product risk and its impact upon young biomedical firms. J Prod Innov Manag 1987; 4: 138-48.

Head W C. Wagner surface replacement arthroplasty of the hip. Analysis of fourteen failures in forty-one hips. J Bone Joint Surg (Am) 1981; 63: 420-427.

Higson $G$. Nonlegislative approaches to the control of medical devices. In: Proceedings of the First International Conference of Medical Device Regulatory Authorities, Pan American Health Organisation, World Health Organization, Washington D C, June 2-61986.

Hippel, von $E$. The dominant role of users in the scientific instrument innovation process. Research Policy 1976; 5: 212-39.

Huiskes R, Strens P H G E, van Heck J, Slooff T J J H. Interface stresses in the resurfaced hip. Finite element analysis of load transmission in the resurfaced hip. Acta Orthop Scand 1985; 56: 474-478.

Huiskes R, Strens P, Vroemen W, Slooff T J J H. Postloosening mechanical behavior of femoral resurfacing prostheses. Clin Mat 1990; 6: 37-55.

Huiskes R. Validility of pre-clinical design analysis relative to endurance of cemented THA. 45th Assembly of SOA, Helsinki. Acta Orthop Scand 1990; Suppl. 237: 61.

Huiskes R. Preclinical testing of noncemented total hip arthroplasty. In: Noncemented Total Hip Replacement (Ed. Küsswetter W). Georg Thieme Verlag, Stuttgart, New York, 1990: 22-36.

Huiskes R. Biomechanics of artificial joint fixation. In: Basic orthopaedic biomechanics (Eds. Mow V C, Hayes W C). Raven Press. New York 1991.

Jobbins B. General considerations in joint replacements. In: An introduction to the bio-mechanics of joints and joint replacement (Eds. Dowson D, Wright V). Mechanical Engineering Publications Ltd. London 1981: 151-61.

Josefsson $G$, Lindberg L, Wilander B. Systemic antibiotics and gentamicin-containing bone cement in the prophylaxis of postoperative infections in total hip arthroplasty. Clin Orthop 1981; 159: 194-200.
Judet J, Judet R, Lagrange J, Dunoyer J. Resection of the hip. Arthroplasty with acrylic prosthesis. E. \& S. Livingstone, Edinburg and London 1954.

Juran J M. (Ed.) Quality control handbook. Mc Graw Hill, New York 1974.

Kahan J S. The ten-years record. Medical Devices and Diagnostic Industry 1986 June: 60-5.

Kiratli B J, Heiner J P, McKinley M, Wilson M A, McBeath A A. Bone mineral density of the proximal femur after uncemented total hip arthroplasty. Transact. 37th ORS, Anaheim, CA, 1991: 545.

Kosekoff J, Kanousse D E, Rogers W H, Mc Closkey L, Monroe Winslow C, Brook R H. The effects of the National Institutes of Health consensus development program on physician practice. JAMA 1987; 258: 2708-13.

Kuehn A A, Day R C. Strategy and product quality. Harvard Business Review 1962: Nov./Dec.; 101-105.

Leary J F M. Mittelmeier ceramic total hip arthroplasty. J Arthroplasty 1988; 3: 87.

Le Vay D. The history of orthopaedics. Carnforth, England 1990.

Liang M H, Katz J N, Phillips Ch, Sledge C, Cats-Baril W, and the American Academy of Orthopaedic Surgeons Task Force on Outcome Studies. The total hip arthroplasty outcome evaluation form of the American Academy of Orthopaedic Surgeons. J Bone Joint Surg (Am) 1991; 73: 639-46.

Medical Device Amendments of 1976, Chapter V of the Federal Food, Drug, and Cosmetic Act of 1938. Pub.L. No. 94-295, 90 Stat. 539: codified at 15 US C par. 55 and 21 US $\mathrm{C}$ passim

Ministère de la Solidarité, de la Santè et de la Protection Sociale. Circulaire relative a l'homologation des produits et appareils à usage préventif, diagnostique ou thérapeutique. Paris le 20 avril 1986.

Ministère de la Solidarité, de la Santé et de la Protection Sociale. Commission Nationale d'Homologation. Procédure d'homologation des prothèses totales d'hanches. Paris, le 17 novembre 1988 .

Mittelmeier H. Ceramic prosthetic devices. In: The Hip (Ed. Welch R B). C.V. Mosby, St. Louis, 1984.

Mogensen A, Ekelund L, Hansson L I, Lidgren L, Selvik G. Surface replacement of the hip in chronic arthritis. Acta Orthop Scand 1982; 53: 929-936.

Muiller M E, Sledge C, Poss R, Schatzker J, Engel C, Paterson D. Report of the SICOT Presidential Commission on documentation and evaluation. International Orthopaedics (SICOT) 1990; 14: 221-29.

Munchow O B. The term "quality". Quality Review Bulletin 1986 September: $310-15$.

Munsey R R, Samuel F F Jr. Medical device regulation in transition. In: 75th Anniversary Commemorative Volume of Food and Drug Law (Ed. The Food and Drug Law Institute). Food and Drug Law Institute Series. Washington 1984: 350-79.

Nissen K I. Introduction. In: Judet J, Judet R, Lagrange J, Dunoyer J. Resection of the hip. Arthroplasty with acrylic prosthesis. E. \& S. Livingstone, Edinburg and London 1954.

Older J. A tribute to John Charnley (1911-1982). Clin Orthop 1986; 211: 23-9. 
Pedersen D R, Crowninshield R D, Brand R A, Johnston R C. An axisymmetric model of acetabular components in total hip arthroplasty. J Biomech 1982; 15: 305- 315.

Pirsig R M. Zen and the art of motorcycle maintenance. Bantam Books, New York 1974. Proceedings and Reports of Universities, Colleges, Councils and Associations: British Orthopaedic Association Annual Meeting 1954. J Bone Joint Surg (Br) 1954; 36: 507- 10.

Reinikainen M. Where goes Germany? Medical Devices and Diagnostic Industry 1987; January: 28.

Ritter M A, Keating E M, Faris P M, Brugo G. Metal-backed acetabular components of total hip replacement: does it reduce loosening? In: Proc. 57th AAOS Mtg, 1990, p.133.

Robinson R P, Lovell T P, Green T M, Bailey G A. Early femoral component loosening in DF-80 total hip arthroplasty. J Arthroplasty $1989 ; 4:$ 55-64.

Rothman R M, Cohn J C. Cemented versus cementless total hip arthroplasty. A critical review. Clin Orthop; 1990; 254: 153-160.

Rudicel S, Esdaile J. The randomized clinical trial in orthopaedics: obligation or option? J Bone Joint Surg (Am) 1985; 67: 1284-93.

Ryd L. Micromotion in knee arthroplasty. A roentgen stereophotogrammetric analysis of tibial component fixation. Acta Orthop Scand 1986: Suppl. 220.

Saha S, Saha P. Bioethics and applied biomaterials. J Biomed Mater Res 1987; 21 (A2): 181-90.

Scales J. Arthroplasty of the hip using foreign materials: a history. In: Proceedings of the Symposium on Lubrication and Wear in Living and Artificial Human Joints, Institution of Mechanical Engineers, London 1966-67; 181 Pt 3J: 63 84.

Safe Medical Devices Act of 1990. Public Law 101-629, 1990.

Schreiber A, Jacob H A C. Loosening of the femoral component of ICLH double cup hip prosthesis. Acta Orthop Scand 1984; 55: Suppl. 207

Sedel L. Normalisation, certification, homologation du matériel orthopédique. Cahiers d'enseignement de la SOFCOT 1987: 381-85.

Sinha M N, Willborn W. W O. The management of quality assurance. John Wiley and Sons, New York 1985.

Staff of House Subcommittee on Oversight and Investigations of the House Committee on Energy and Commerce. Report on medical device regulation: the FDA's neglected child. 98th Congress, 1st Session. Comm. Print 98-F 1983.

Strens P H G E. Analysis of implant failure in the Wagner resurfacing arthroplasty. Doctoral dissertation, University of Nijmegen, The Netherlands, 1986.

Sunday Times. The Thalidomide children and the law. Andre Deutsch, London 1973.

Thompson R J. Testimony. Senate Committee Report on the Medical Device Amendments of 1976, 94th Congress Report No. 94-33.

Tuchman B W. The decline of quality. New York Times Magazine 1980; November 2.

Tuip N J A. Polyethylene delamination in the PCA total knee. Material analysis in two failed cases. Acta Orthop Scand 1992; 63: 263-266.

Tulp N J A. Wear and alignment in total knee replacement: an in vivo and laboratory study. Doctoral Dissertation, University of Nijmegen, The Netherlands, 1993 (in press).
Wagner H. Surface replacement arthroplasty of the hip. Clin Orthop 1978; 134: 102-130.

Waugh W. John Charnley, the man and the hip. Springer Verlag, London 1990

Wet van 15 januari 1970, houdende regelen met betrekking tot medische hulpmiddelen (Wet op de medische hulpmiddelen). Staatsblad 1970, 53.

Wright T M, Rimnae C M, Stulberg S D, Mintz L, Tsao A K, Klein R W, McCrae C. Wear of polyethylene in total joint replacement: Observations from retrieved PCA knee implants. Clin Orthop 1992; 276: 126-134.

Wroblewski B M. 15-21 Year results of the Charnley lowfriction arthroplasty. Clin Orthop 1986; $211: 30-5$. 